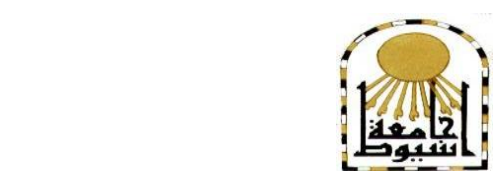

كاية التزبية لاطفملة المبكرة

إدارة البممث والنشر العالمي (المبلة العلمية)

$==\boldsymbol{=}=\boldsymbol{=}$

\title{
بعض المعوقات التى تواجة تنفيذ أنشطة التربية الهركية فى رياض الأطفال فى ظل المنهج الجديد (2,0) بمحافظة المنيا (مدينة المنيا)
}

$$
\text { إعــــداد }
$$

د/ طارق سلام سيد أهمد سلام

مدرس بكلية التربية للطفولة المبكرة

$$
\text { جامعة أسيوط التهابل }
$$

$$
\text { (العدد الحادى عشر- أكتوير } 9 \text { (ب)م) }
$$




\section{ملخص}

بالرغم من أهمية التربية الحركية باعنبارها مدخلا طبيعيا لتمية شاملة متكاملة للطفل فى سنواته الأولى إلا أنها لا تلقى العناية الواجبة من القائمين على رياض الألطية لألفال

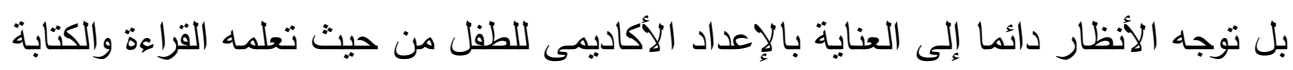

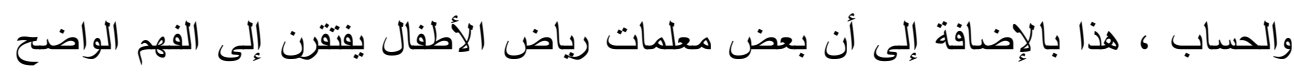

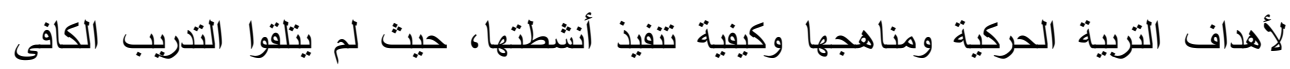
لتأهليهم لهذا العمل وخاصة فى ظل المنهج الجديد (2,0) بعد أن أدخلت وزارة التربية والتعليم والتعليم الفنى بمصر تعديلا جديدا على نظام الدراسة فى مؤسسات رياض الأطفال

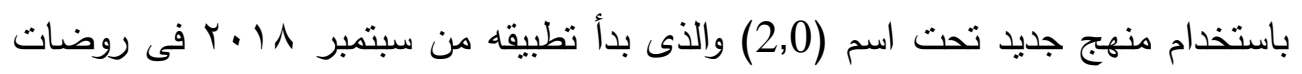
جمهورية مصر العربية.

وقد لاحظ الباحث من خلال عمله بالكلية وإشرافه على مجموعات التربية العملية

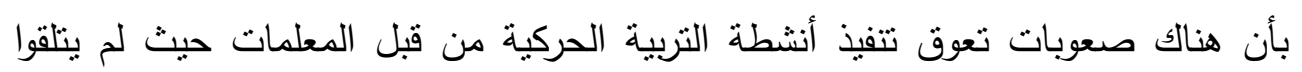

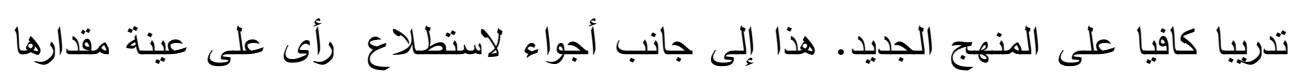

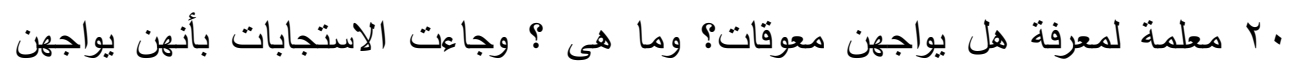
صعوبات حقيقية من حيث نقص التدريب على المنهج الجديد (2,0) ونقص الأجهزة والساحات لنتفيذ الأنشطة إلى جانب ازدحام القاعات بالأطفال وضيق المكان. هذا إلى جانب أن العديد من الدراسات أثتبت أن هناك معوقات نواجه معلمات

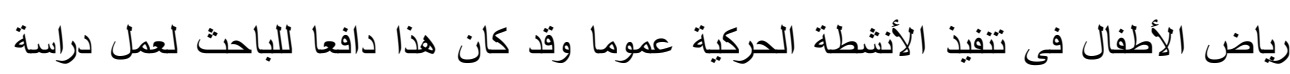
عن بعض معوقات تتفيذ أنشطة التربية الحركية فى ظل المنهج الجديد وعلى هذا تحدد الانه

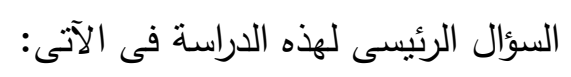

ما هى بعض معوقات تتفيذ أنثطة التربية الحركية برياض الأطفال فى مدينة المنيا فى ظل المنهج الجديد (2,0) من وجهة نظر المعلمات. 
يتفرع عنه أسئلة عن: المعوقات المرتبطة بالبرنامج، والمعوقات المرتبطة بالمعلمات ثم المعوقات المرتبطة بطفل الروضة والمعوقات المرتبطة بإدارة الروضة وفى النهاية المعوقات المرتبطة بالتوجيه الفنى.

وقد هدفت الدراسة إلى محاولة الكثف عن بعض المعوقات التى تواجه معلمات رياض الأطفال فى ظل المنهج الجديد (2,0) بمدينة المنيا (محل إقامة الباحث) من وجهة

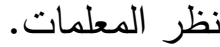

ولكى تحقق الدراسة أهدافها تم استخدام المنهج الوصفى وتصميم استبانة تكونت

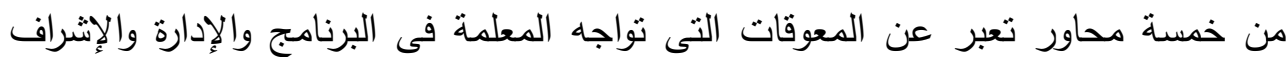
الفنى وما برتبط بالمعلمة والطفل وتضمن كل محور عشرة معوقات. نم تطبيق الاستبانة على عدد سم معلمة من الروضات الحكومية بمدينة المنيا. وقد توصل الباحث لمجموعة من النتائج كان أهمها :

اتفاق أفراد العينة من الروضات المختلفة على أن أهم المعوقات فى تتقيذ أنشطة التربية الحركية فى ظل المنهج الجديد (2,0) هى: 1 - نقص التدريب على المنهج الجديد وعدم كفاية فترة هذا التدريب. r- نقص الإمكانيات المكانية من حيث الساحات المخصصة للنشاط الحركى والأجزة

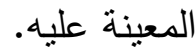
r- ضعف الدعم المقدم من إدارة الروضة ومن الإشراف الفنى لتشجيع المعلمات على مواجهة صعوبات نتفيذ الانشاط الحركية. وقد توصلت الدراسة إلى عدد من التوصيات كان أهمها: 1 - عقد دورات تدريبية مكثفة للمعلمات للتدريب على المنهج الجديد $(2,0)$. r- ضرورة توفير الإمكانيات المكانية والمادية والأجهزة لجميع الروضات من قبل الإدارة. 
مجلة " دراسات في الطفولة والتربية" - جامعة اسيوط

r- إطلاع كليات رياض الأطفال والتربية للطفولة المبكرة بمسؤليتها فى تدريب

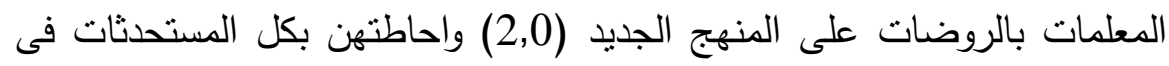
مجال التربية الحركية وإدخال المنهج الجديد فى مفردات الكلية. ع - يوصى الباحث بضرورة تقديم التدريب قبل البدء فى تتفيذ أى منهج جديد فى الروضات فى مجال التربية الحركية وإمداد المعلمات بالتطبيقات على المنهج.

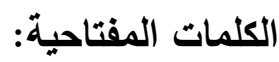
المعوقات - التربية الحركية - المنهج الجديد (2,0) - معلمات رياض الاطفال 
د/ طارق سلام سيد أحمد سلام

بعض المعوقات التى تواجة تنفيذ أنشطة

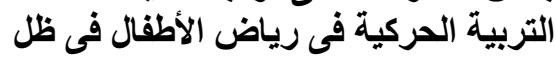

المنهج الجديد (2,0) بمحافظة المنيا (مدينة المنيا)

\title{
Obstacles Impeding the Implementation of Movement Education Activities at Kindergartens in the Light of the (2.0) New Curriculum in Minia Govermorate (Minia City).
}

\begin{abstract}
The current study targets the detection and explorations of the obstacles combating the female kindergarten teachers and the children dealing with the new curriculum (2.0) from the point of view of these teachers. In order for this study to achieve its main objectives, the researcher has designed a questionnaire divided into five axes representing the obstacles confronted by kindergarten teachers. These obstacles highlight major issues such as the program, administration, technical supervision and some other issues related to children and the teachers. Each axis includes ten difficulties or obstacles; the questionnaire has been administrated to 33 kindergarten female teachers teaching at public kindergartens in Minia city.
\end{abstract}

A number of significant conclusions have been reached; which are cited as follows:

1- It has been revealed that there is a shortage in training with regard to the new curriculum.

1- There is also shortage in spatial potential, locations, and equipments dedicated for physical activities.

2- Poor Support contributed by the kindergarten administration force and the technical supervision to motivate the teachers to confront the difficulties of the implementation of movement activities.

A number of recommendations have also been submitted, among them are the following:

1- There should be intensive training sessions for female teachers to assist them to get accustomed to and be fully aware of the new curriculum (2.0).

العدد الحادى عشر - أكتوبر 19. مr 
2- Spatial, materialistic capabilities and equipments should be provided by the administrative force for all kindergartens.

3- Colleges of kindergarten and early childhood education should be aware of their responsibility in training kindergarten teachers on the new curriculum (2.0) and getting them fully acquainted with the latest updates in the field of movement education in addition to including the new curriculum (2.0) among college priorities.

4- It is recommended by the researcher to provide training before the beginning of the implementation of any new curriculum (2.0) in kindergartens in the field of movement education and supply kindergarten teachers with the necessary applications on the curriculum.

\section{Key words:}

Obstacles - Movement Education - New Curriculum (2.0) Kindergarten Female Teachers. 
تعتبر مرحلة رياض الأطفال من أهم المراحل التربويـة التعليميـة التى تسـاهم فى

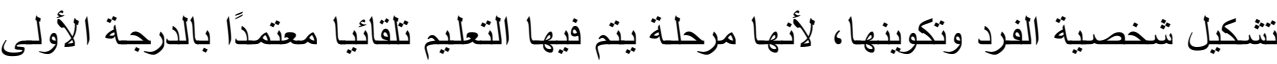
على النشاط الحر للطفل، وتعد التربية البدنية وبرامجها المختلفة من أنجح الوسائل التربوية، لهنه التى تهدف الى تحقيق النمو الثامل للطفل فالحركة هى احدى الدوافع الأساسية لنمو الطفل حيث يشير جالاهو (Gallahue, 1996) الى أن الطفل يبدأ التعرف على البيئة المحيطة به من خلال الحركة ويعتبر هذا الميل الطبيعى للحركة هو أحد طرق التعلم. لهذا يجب أن تكفل مؤسسات رياض الأطفال حرية الحركة لأطفالها معتمدة على

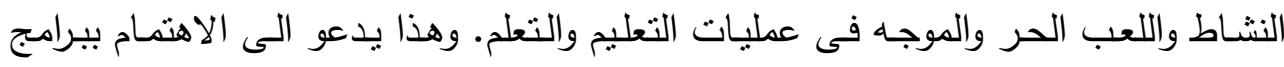

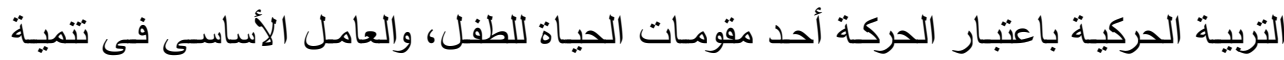

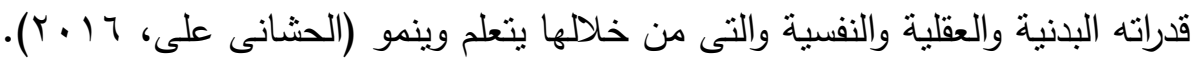
لذلك أولت بعض الدول المنقدمة عناية فائقة لطفل هذه المرحلة وتتميته بدنبا وعقليا بحيث تهيئة للمراحل المدرسية التالية وتساعده فى مواجهة بعض المشكلات النفسية التى قد يتعرض لها نتيجة انتزاعه من البيئة الداخلية التى اعتادها داخل المنزل. وتعتبر التربية الحركية أفضل الأساليب التعليمية التى تنتهدف تعليم الفرد وتدريبه فى مرحلة رياض الأطفال. فمن خلالها يتعلم الطفل كيف يفهم ويتحكم فى الطرق العديدة التى يتحرك منها جسمه، والتربية البدنية لها آثار صحية على كلا من الطفل والبالغ حيث أثتتت الأبحاث أن التربية البدنية تحسن من صحة الأطفال مبكرًا فى سن الرابعة تومونز

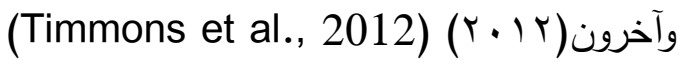

وقد اشـار كلاً من Basch, 2010, Trudean \& Sheoard, 2008 الى أن الأطفـال الأكثر صـحة هـم أفضـل المتعلمـين وأن التربيـة البدنيـة بمكـن أن تحسـن الأداء الأكاديمى للطفل وتؤثر على كافة الجوانب الأخرى والتى نساهم فى شمولية نمو الطفل، إلا

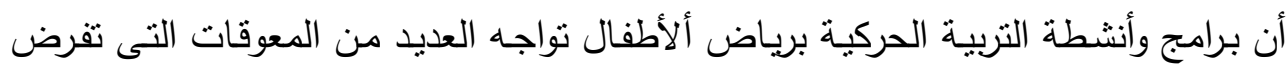
علينا دراستها ومحاولة ايجاد الحلول المناسبة لها ليتم النمو الثشامل للطفل. 
بـالرغم من أهيـة التربيـة الحركية باعتبارهـا مدخلاً طبيعيـا لتتميـة شـاملة متكاملـة

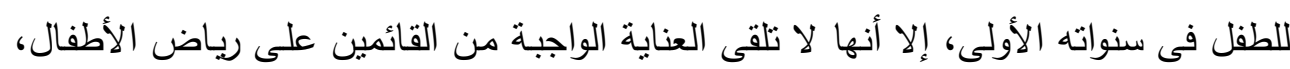

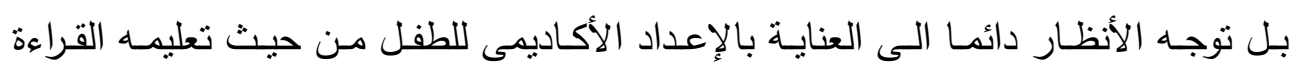
والكتابة والحساب. هذا بالإضـافة الى أن بعض معلمات رياض الأطفال يفتقرن الى الفهم الواضح لأهداف التربية الحركية وكيفية تتفيذ أنشطتها حيث لم يتلقوا التدريب الكافى لتأهيلهم لهذا العمل وخاصـة فى ظل المنهج الجديد (2,0)، حيث أدخلت الوزارة فى مصر تعديلاً جديدًا على نظام الدراسة فى الروضات باستحداث منهج جديد تحت اسم (2,0) بدا تطبيقه

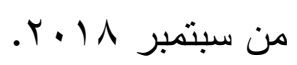

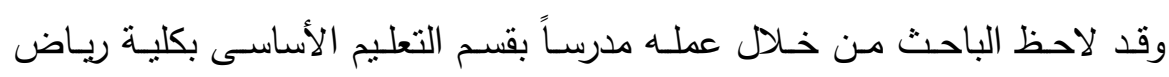

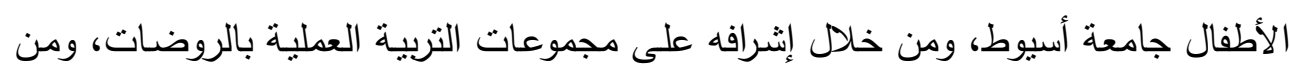

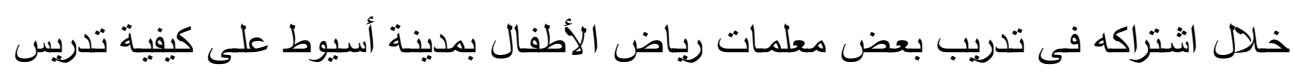
الثـق الانجليزى من البرنـامج الجديد (2,0) فى دورة تدريبيـة تابعـة لكليـة ريـاض الأطفال

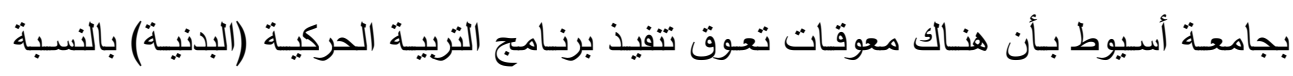

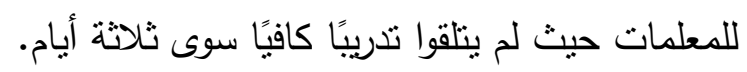

وقد دفع هذا الباحث لعمل استطلاع رأى لعينة مقدارها ( ب r) معلمة من معلمات

الروضات المختلفة اللاتى حضرن الدورة التدريبية، وقد تضمنت الاستمارة سؤالاً مفتوح وهو : هل تقابلك معوقات فى تتفيذ وتدريس أنشطة التربية الحركية فى ظل المنهج الجديد إذا كانت

$$
\text { الإجابة نعم فما هى هذه الصعوبات؟ }
$$

وقد جاءت الإجابة بنعم بنسبة . . 1\% لجميع أفراد العينة، أى وافقوا على وجود

صعوبات، وجاءت الإجابات عن سؤال ما هى الصعوبات كالتالى:

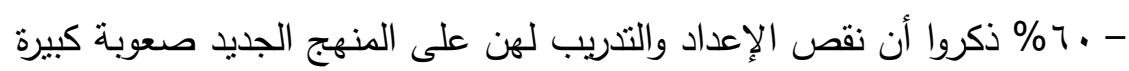

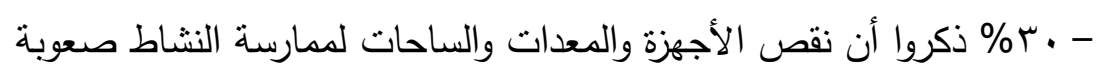
- . 1\% ذكروا أن ازدحام الفصول بالأطفال وضيق المكان يمنل صعوبة. 
يتضـح من نتائج الدراسـة الاستطلاعية أن تطبيق المنهج الجديد (2,0) لم يسبقه تدريب كاف، وأن قاعات الروضـات ليست مجهزة، ولا مهيأة للنطبيق حيث يزدحم الأطفال فى فصول ضيقة الى جانب قلة توفر الساحات المناسبة لممارسة النشاط.

هذا الى جانب أن العديد من الدراسات أثتبت أن هناك معوقات تواجه المعلمات فى

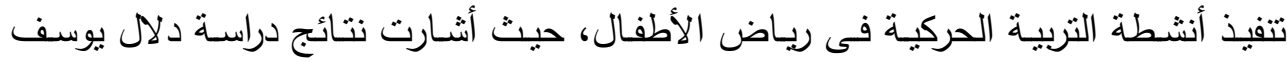

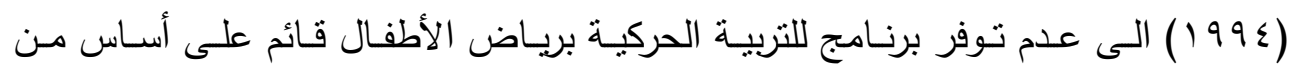
التخطبط الجيد والأهداف الواضحة التى نتاسب طفل هذه المرحلة.

كما أثشارت نتائج دراسة أحمد عبد العظيم (997 (1) الى أن هناك معوقات خاصـة بعدم وضوح أهداف التربية الحركية ومعوقات مرتبطة بعدم كفاية الإعداد الفنى للمعلمة، كما

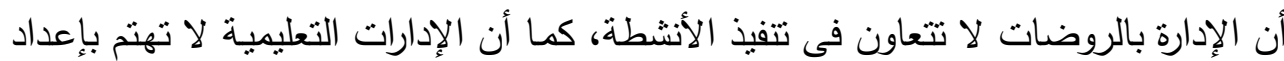
اختبارات فى مادة التربية الحركية.

كما أكدت نتائج دراسـة أحمد السـرهيد (Y . . r) على عدم وجود برنـامج للتربيـة الحركية مدروس ومبنى على اسس علمية ينم تطبيقه فى رياض الأطفال وما ينت تطبيقه

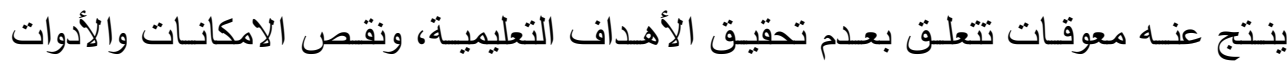
المساعدة وعدم كفاية الإعداد المهنى للمعلمات.

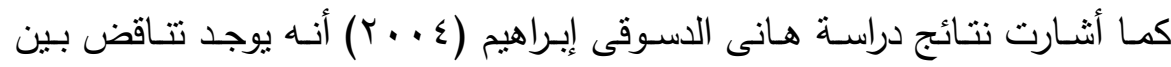

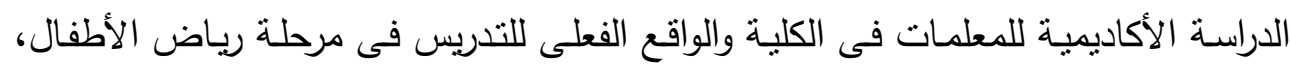

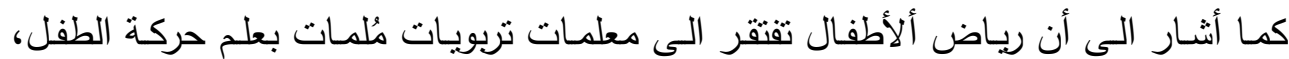
والدورات التدرييية للمعلمات لصقل وزيادة خبراتهن فى مجال التربية الحركية ومستحدثاتها.

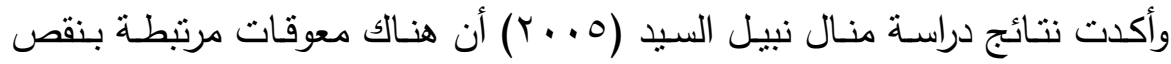
الامكانـات الماديـة والبشـرية مـن حيث الاعداد والتـدريب للمعلمـات ومـن حيث عدم توفر الأماكن والمساحات المتاحة لممارسة الأنشطة.

Sevimili-Celik \& Jonsons, 2013 أن أبرز المعوقات التى تواجه المعلمات فى تتفيذ أنشطة التربية الحركية 


\section{مجلة " دراسات في الطفولة والتربية" - جامعة اسيوط}

هى أن إعدادهن بالكلية لم يكن كافيا لجعلهن يُدرسن التربية الحركية كما كان تدريبهن أثناء الخدمة غبر فعال.

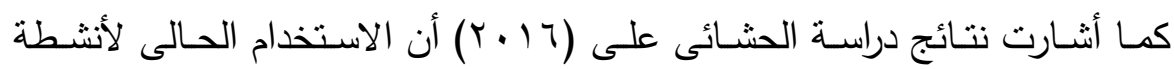

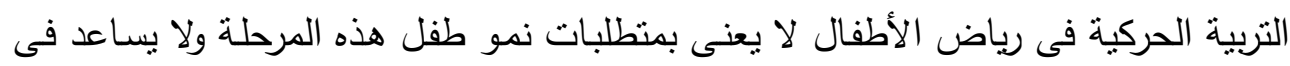

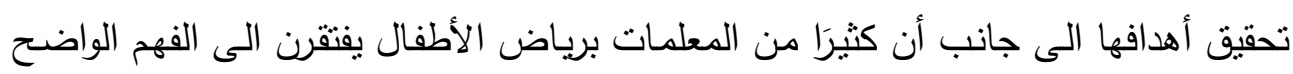

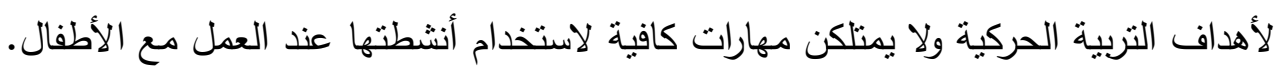
وهكذا تبلور إحساس الباحث بمشكلة البحث من خلال ملاحظاته وتطبيقه لاستمارة الاستطلاع الى جانب مـا أظهرته نتائج الدراسات السـابقة فى مجال معوقات تنفيذ أنشطة

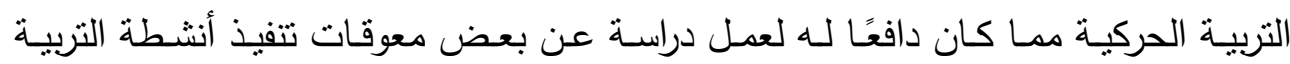

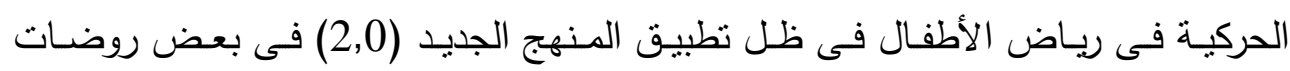

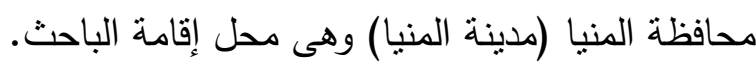
وعلى هذا يتحدد السؤال الرئيسى لهذه الدراسة فى الآتى:

ما هى بعض معوقات تتفيذ أنشطة التربية الحركية برياض الأطفال فى ظل المنهج الجديد (2,0)؟ ويتفرع منه الأسئلة الآتية:

- ما المعوقات المرتبطة ببرنامج التربية الحركية فى ظل المنهج الجديد (2,0) ؟ - ما المعوقات المرتبطة بمعلمات رياض الأطفال فى ظل المنهج الجديد (2,0) ؟ - ما المعوقات المرتبطة بالامكانات المتاحة بالروضة فى ظل المنهج الجديد $(2,0)$ - ما المعوقات المرنبطة بإدارة الروضة فى ظل المنهج الجديد (2,0)؟ - ما المعوقات المرتبطة بالتوجيه الفنى فى ظل المنهج الجديد (2,0)؟ - ما المقترحات التى تمكن من الاستفادة من تطبيق المنهج الجديد (2,0) فى روضات مدينة المنيا 


$$
\text { بهدف البحث الحالى الى }
$$

محاولة الكثف عن بعض المعوقات التى نواجه تتفيذ أنشطة التربية الحركية فى

$$
\text { رياض الأطفال فى ظل المنهج الجديد (2,0) وذللك من خلال: }
$$

1- التعرف على المعوقات الخاصـة ببرنامج التربية الحركية (البدنية) فى ظل المنهج

$$
\text { الجديد }
$$

r - التعرف على المعوقات الخاصة بمعلمات رياض الأطفال فى ظل المنهج الجديد r- التعرف على المعوقات الخاصة بإدارة رياض الأطفال فى ظل المنهج الجديد ؟ - التعرف على المعوقات الخاصة بمدى نوفر الامكانات والأدوات والأجهزة فى ظل المنهج الجديد ه- التعرف على المعوقات الخاصة بالتوجيه الفنى فى ظل المنهج الجديد צ- محاولة التوصل الى مقترحات للاستفادة من تطبيق المنهج الجديد فى روضـات

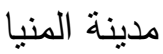

\section{أهمية البحث:}

\section{تتمثل أهمية البحث الحالى فى الآتى:}

1- المساهمة فى دراسة المعوقات التى تواجه تطبيق المنهج الجديد (2,0) بالروضات يساعد فى اكتشافها ومعرفة نقاط القوة والضعف فى النطبيق ومحاولة إيجاد الحلول المناسبة لمواجهة هذه المعوقات لمعالجتها وسيكون لهذا مردودًا تعليميًا وتربويًا

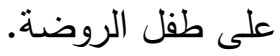
ץ- قد يفتح البحث الحالى آفاقًا أرحب فى مجال الكثف عن المعوقات التى تواجهـ تتفيذ أنشطة التربيـة الحركيـة فى رياض الأطفال خاصـة فى ظل المنهج الجديد 


\section{مجلة " دراسات في الطفولة والتربية" - جامعة اسيوط}

حيث يعتبر هذا البحث امتدادًا للدراسات السابقة، كما يعد تمهيدًا لدراسات أخرى جديدة.

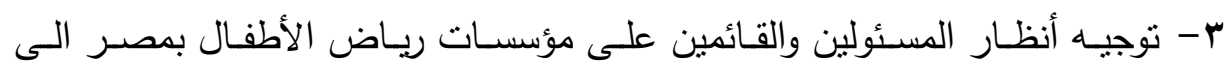

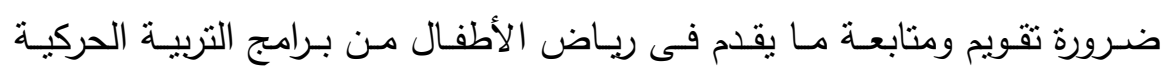

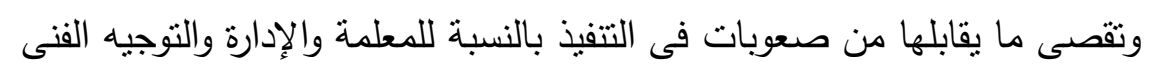
ـ - قد تكون هذه هى الدراسة الأولى التى تبحث فى معوقات تطبيق المنهج الجديد

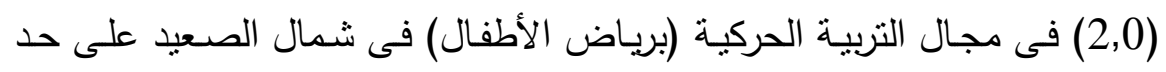

\section{علم الباحث}

\section{منهج البحث وأدواته:}

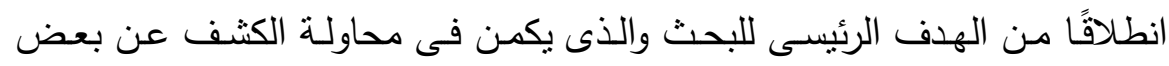

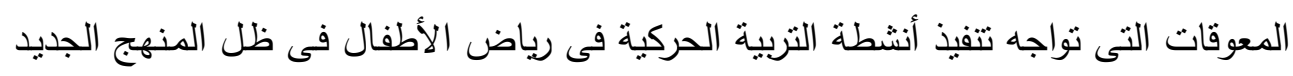

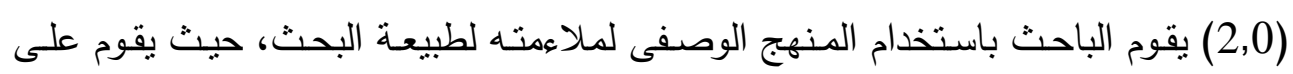

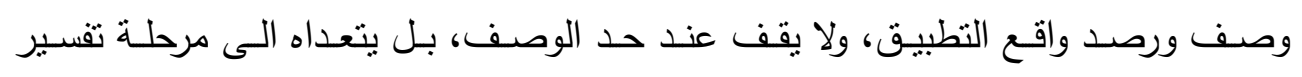
المعلومات وتحليلها واستخلاص دلالات ذات مغزى تفيد فى الوقوف على ابعاد المشكلة.

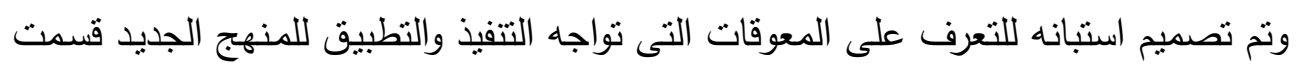

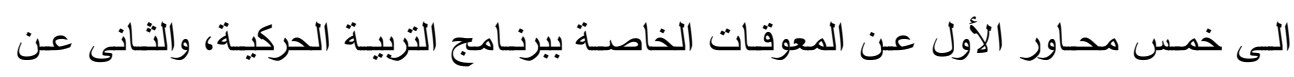

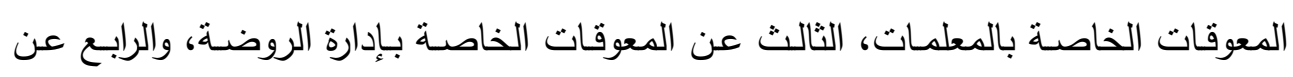

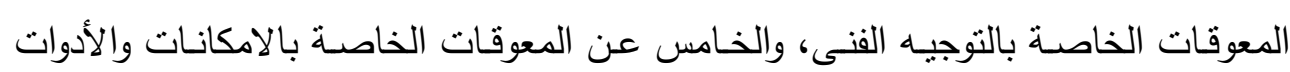
والأجهزة، وقد تم توزيع الاستبانة على عينة من المعلمات والموجهات فى روضات ولتهات مدينة

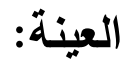

تم اختيار (Tr) معلمـة بطريقة عشوائية مـن بين عدد المعلمـات اللاتى حضـرن

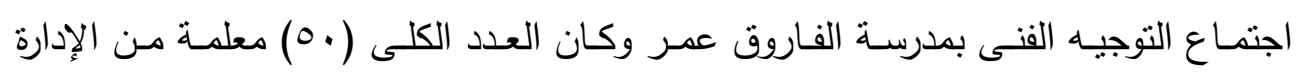


التعليمية بمدينة المنيا، كما تم اختيار جميع الموجهات حيث عددهن الكلى (1') احدى عشر موجهه

\section{حدود البحث:}

يلتزم البحث بالحدود الآتية:

- الحدود البشرية: تمثلت فى عدد (rr) معلمة، (1) موجهات

- الحدود الموضوعية: اقتصر البحث الحالى على دراسة المعوقات التى تواجه بعض المعلمات والموجهات فى تتفيذ أنشطة التربية الحركية فى ظل المنهج الجديد $(2,0)$ فى روضات مدينة (المنيا) محل إقامة الباحث

- الحدود المكانيـة: تضـمنت العينـة عدد (rr) معلمـة، (1) موجهه مـن إدارة المنيا التعليمية من الروضات الحكومية بمدينة المنيا

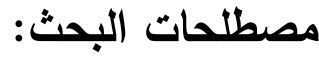

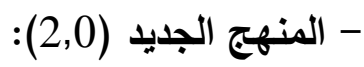

أثنـارت وزارة التربية والتعليم والتعليم الفنى إلى إن إنـارة البدء فى التغيير الجذرى

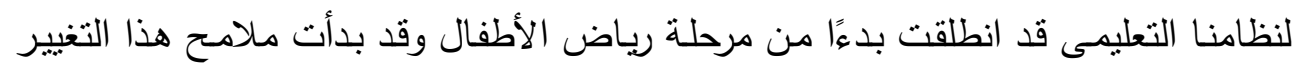

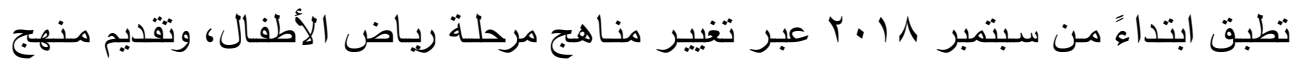

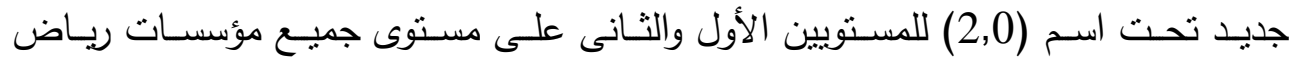

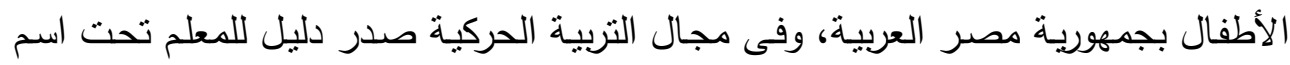
"التربية الرياضية، مرحلة رياض الأطفال". وسوف يتم عرضه بالتفصيل فى الاطار النظرى.

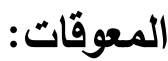

هى العوامل المختلفة التى تعوق تحقيق أهداف التربية الحركية سواء كانت معوقات مادية أو بشرية أو الأثثين معًا. وحددها الباحث فى (معوقات خاصة ببرنامج التربية الحركية

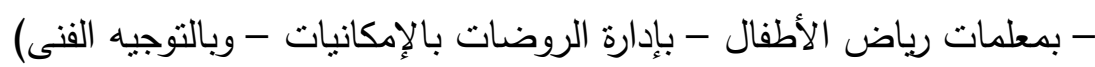


التربية الحركية:

هى نظام تربوى مبنى بشكل أساسى على الامكانات النفس حركية الطبيعية المتاحة

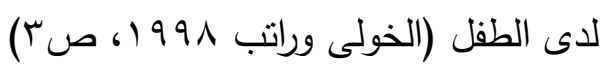

$$
\begin{aligned}
& \text { مرحلة رياض الأطفال: }
\end{aligned}
$$

هى مرحلة تعليمية تهتم بتربية الأطفال صغار السن ويدور برنامجها التزبوى حول

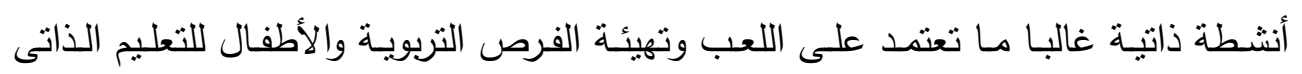

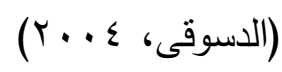

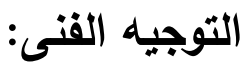

هو نثاط تربوى موجه يقوم به مجموعة من الخبراء فى الإنشراف الفنى ويهدف الى ونى

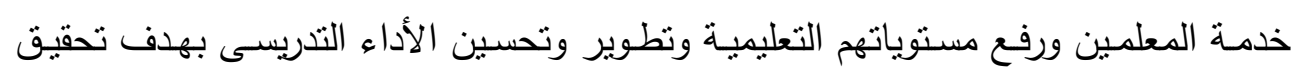
الأهداف التعليمية المرغوب فيها (الكفانى، 1997 (1).

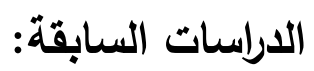

في ضوء ما أطلع عليه الباحث من الدراسات السابقة والمرتبطة بمجال الدراسة الحالية أمكن التوصل الى الدراسات التالية وهى مرتبة من الأحدث الى الأقداد:

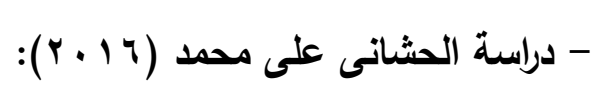

بعنوان: معوقات استخدام أنشطة وبرامج التربية الحركية بمؤسسات رياض الأطفال

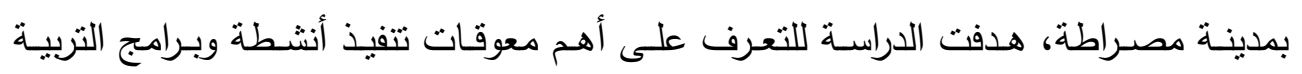

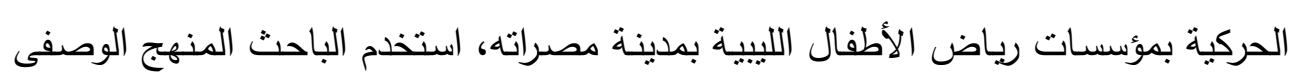

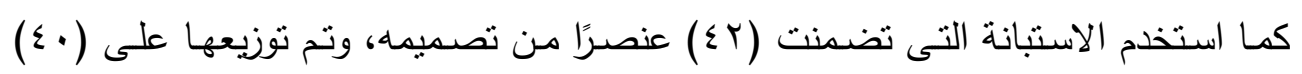

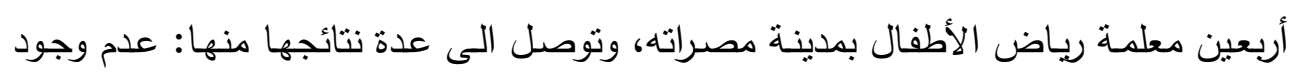

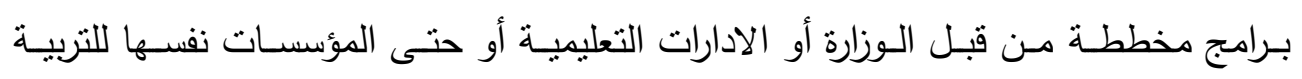

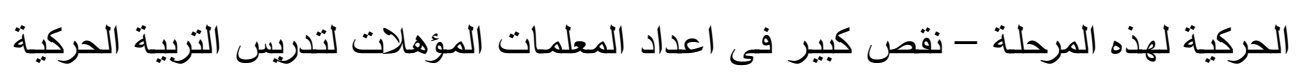


فى هذه المرحلة - عجز فى الساحات والملاعب والصالات الخاصة بتتفيذ التربية الحركية لأطفال هذه المرحلة الى جانب نقص الامكانات والأدوات والأجهزة الخاصـة بتتفيذ أنشطة وبرامج التربية الحركية بمؤسسات هذه المرحلة.

وقد أوصسى الباحث بـأن تتولى هيئة علميـة متخصصـة التخطبط لبرامج التربيـة الحركيـة لهذه المرحلة وتطوير برامج اعداد المعلمات قبل الخدمة باقسام رياض الأطفال

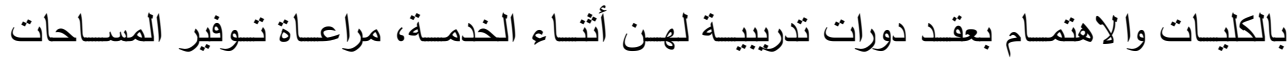
والامكانات والأجهزة بالرياض وتزويد المعلمات بأدلة لتساعدهم فى تتفيذ الأنشطة

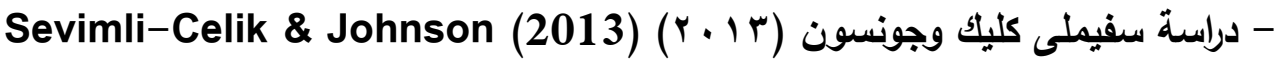
بعنوان: "احتاج للحركة وكذللك يحتاج الأطفال"، هدفت الدراسـة الى التأكيد على أهمية التربية الحركية برياض الأطفال وإظهار بعض المشكلات التى تعانى منها معلمات الرياض حيث أظهرت دراستهما أن (اب7\%) من المعلمات كانوا على وعى بأن معلوماتهم

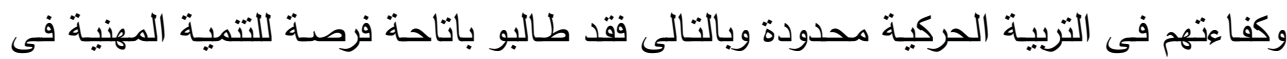

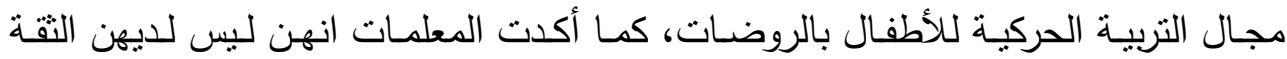
الكافية فى جعل الأطفال بقدرون الأنشطة الحركية وأن التربية الحركية التى تلقوها بالإعداد فى الكلية غير كافية لجعلهن يدرسون التربية الحركية مما يمنل معوقا فى تتفيذ برامج التربية

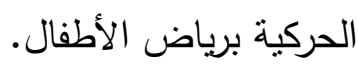

- دراسة (2008) Stdrk, S. \& Sanders, S. W. بعنوان: "التربية البدنية فى تربية الطفولة المبكرة"، والتى هدفت الى بيان العلاقة القوية

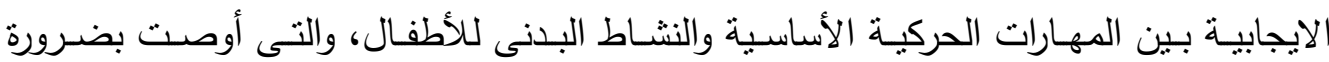
الاهتمام ببرامج التربية البدنية من حيث الهدف ومضمون البرنامج والتنديب المسبق للمعلمات. - دراسة على أبو عجيلة الزروق (ه . . ب): بعنوان: "بعض المشكلات التى تواجه تتفيذ برنامج التربية الحركية بمرحلة رياض

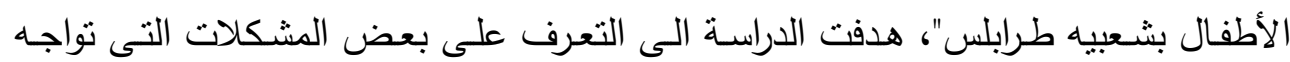




\section{مجلة " دراسات في الطفولة والتربية" - جامعة اسيوط}

تتفيذ برنامج التربية الحركية بمرحلة رياض الأطفال من وجهة نظر المعلمات بهذه الشعبية،

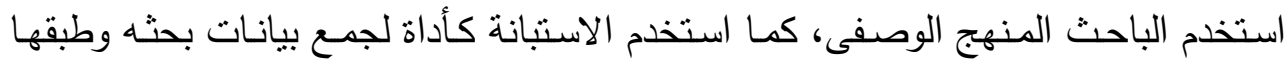

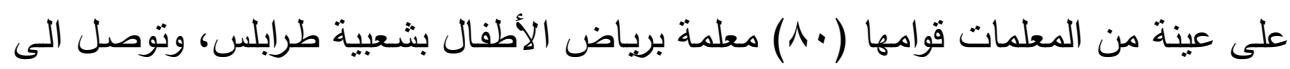

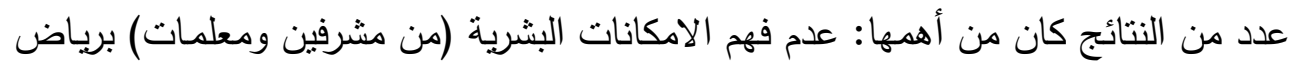

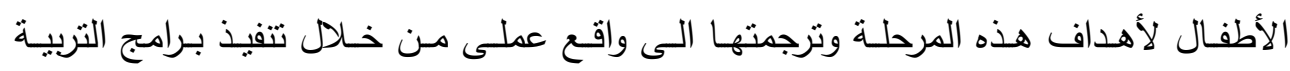

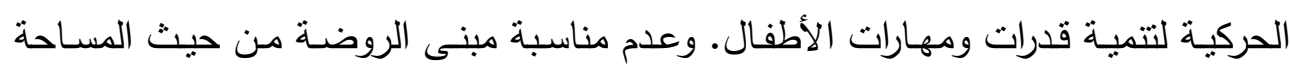

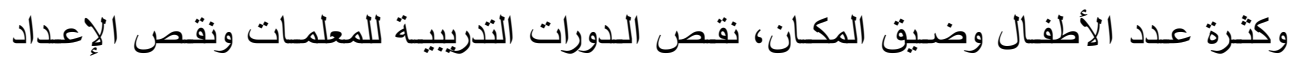
والتأهيل للتدريس والإثراف برياض الأطفال.

$$
\text { - دراسة منال نبيل العمرى (ه . . ب): }
$$

بعنوان: "برنـامج مقترح للتغلب على معوقات استخدام التربيـة الحركيـة فى منهج

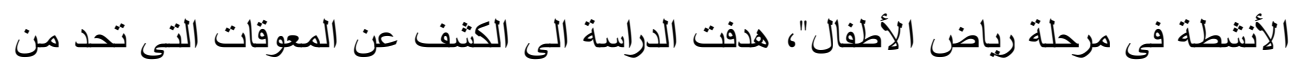
تقديم واستخدام التربية الحركية فى منهج الأنشطة برياض الأطفال، وتقديم تصسور مقترح

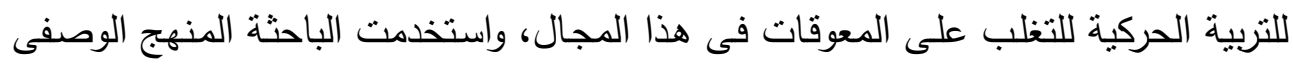

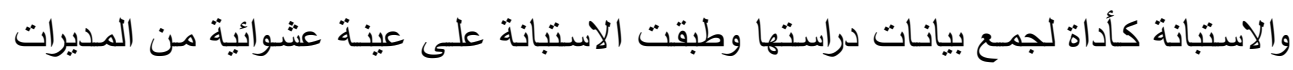
والمعلمات العاملات بروضـات مدن محافظة الغربية الحكومية (من مدينتى طنطا والمحلة الكبرى) لتحديد المعوقات من وجهة نظرهم، توصلت الى مجوموعة من النتائج كان أهمها:

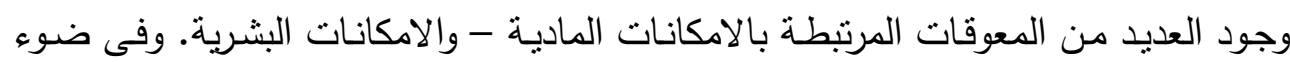
هذه المعوقات أعدت الباحثة برنامج للتغلب على هذه المعوقات بيسر ممارسـة الأنشطة

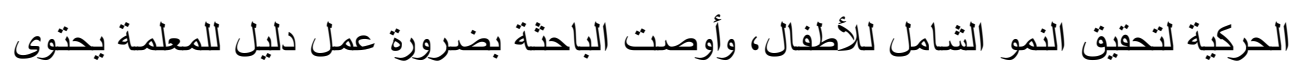
على برامج حركية، والاهتمام بعمل ورش عمل لمعلمات رياض الأطفال فى مجال التربية لئل

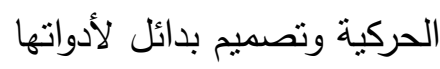
- دراسة (2005) (Barroso et al., باروسو وآخرون بعنوان: "بعض المعوقات التى تواجه تتفيذ التربية الحركية من المتخصصين فى رئ التربية البدنية بولاية تكساس الأمريكية"، حيث هدفت الدراسة الى تحديد بعض المعوقات الثـائعة 
التى تحد من تدريس التربية الحركية والبدنية فى روضـات الأطفال، وقد توصلت الدراسـة الىى نتائج كان من أهمها: هامشية التربية الحركية، أى عدم الاهتمام بها كمادة أساسية، وقلئية وقلة الموارد

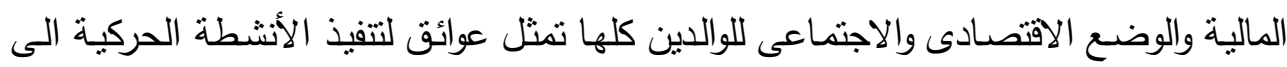
جانب استخدام الممارسات التدريسية غير المناسبة والتى لم تُؤهل لها المعلمة.

Seidu Sofo \& Esola دراسة سيديو صوفو واسولا (2004) بعنوان: "العقبات التى تواجه تدريس الأنشطة الحركية والبدنية فى رياض الأطفال

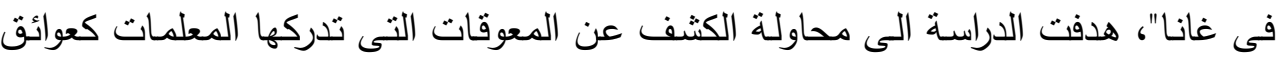

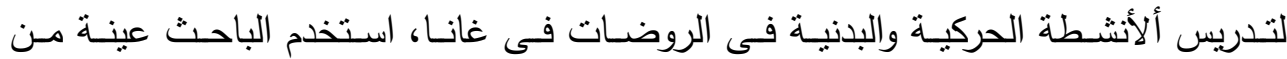

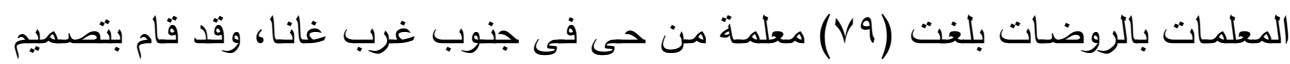
استبانة احتوت على (1) (1) عنصرًا لجمع بيانات دراسته، وقد تم تحليل البيانات مستخدمًا الاحصاء الوصفى الاستتناجى وقد أظهرت النتائج أن حجم الفصل الدراسى يتراوح عدده من

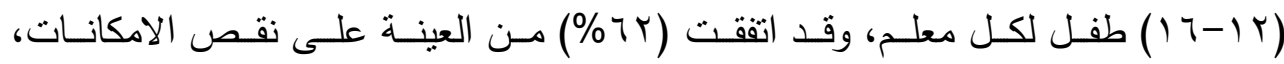

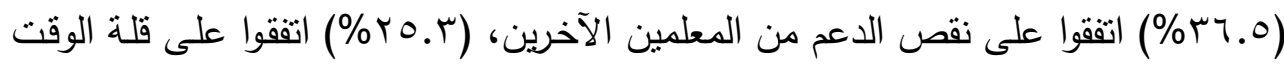

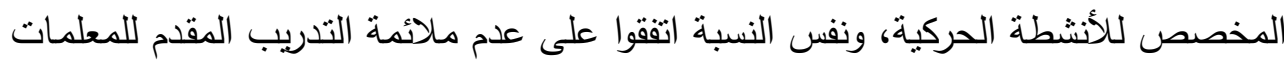
كل هذه المعوقات اعتبرت عوائق كبيرة فى تدريس الأنشطة الحركيـة والبدنيـة، استخدم الباحث اختبار (ت) One-Way Anova وتحليل Anova لمعرفة أثر النوع، الفصل ولئل

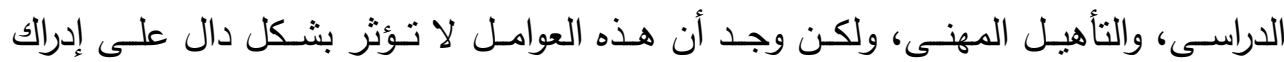

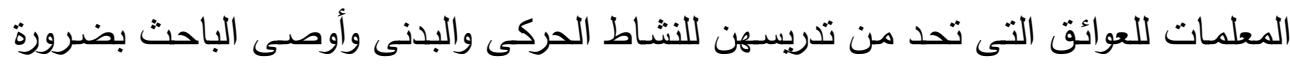

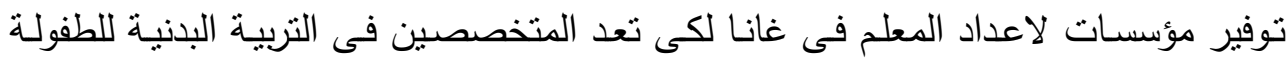

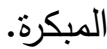

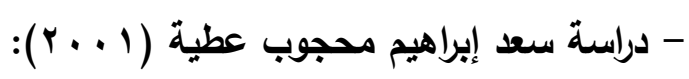

بعنوان: دراسة تحليلية لبرامج التربية الحركية فى رياض الأطفال بمحافظة الجيزة،

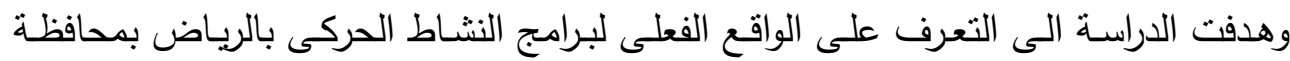

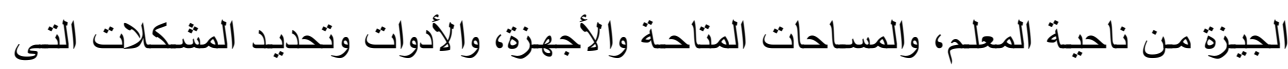




\section{مجلة " دراسات في الطفولة والتربية" - جامعة اسيوط}

تواجـه تتفيذ بـرامج النشـاط الحركى، اسـتخدم الباحث المـنهج الوصـفى المسـى واستعان

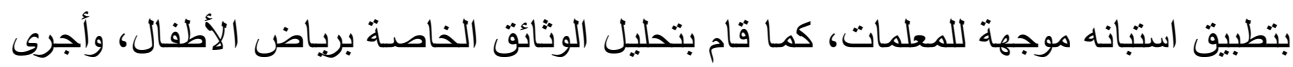
ملاحظة ومقابلة شخصية وتوصل الى مجموعة من النتائج كالتالى: - الأهداف الخاصة برياض ألأطفال لا تتضمن الجوانب البدنية الحركية والنفسية معًا - لا توجد برامج مخططة للنشاط الحركى لأطفال هذه المرحلة - لا يوجد مشرفون متخصصون للنشاط الحركى فى الروضات - لا توجد ميزانية مخصصة للنشاط الحركى فى الروضات

- دراسة أحمد عبد العظيم عبدالله (997 19):

وعنوانهـا: "مشـكلات التربيـة الحركيـة فـى ريـاض الأطفــال بمحافظــة الدقهليـة"،

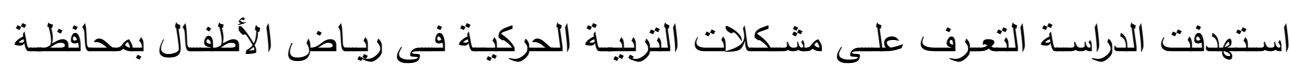

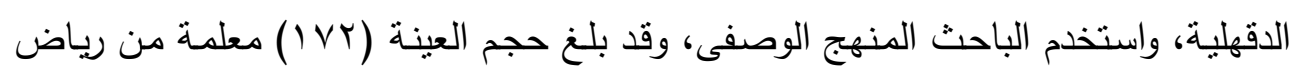

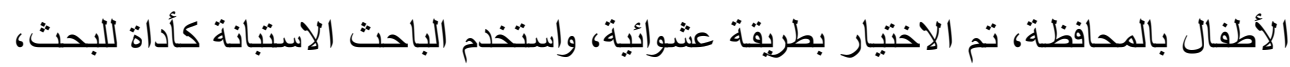
وتم تطبيقها على العينة السابقة الذكر وتوصل الى عدد من العناصر التى تمثل مشكلات

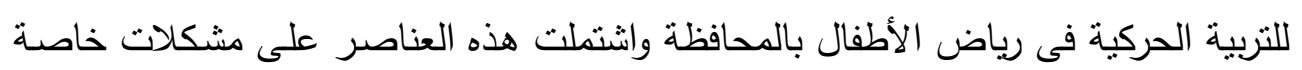
(بأهداف التربية الحركية - بالاعداد المهنى للمعلمة- ثم برامج التربية الحركية)

- دراسة نجوى سليمان متولى (1991 )

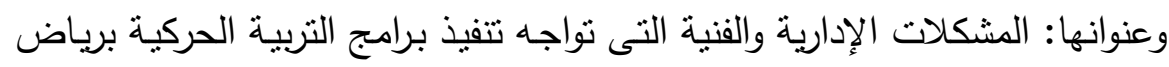

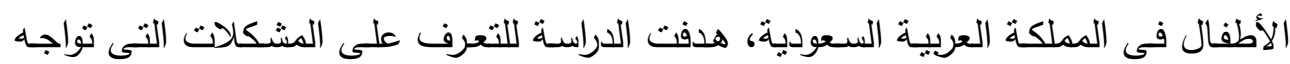

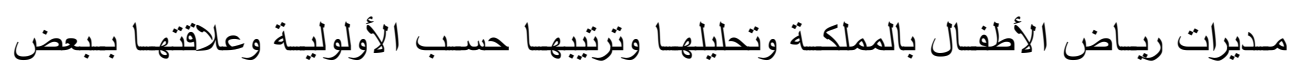

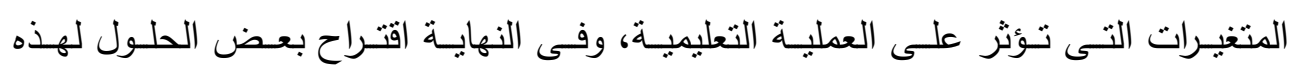
المشكلات. واستخدمت الباحثة المنهج الوصفى، وقد اختارت العينة بطريقة عمديـة تمنلت فى (ع Y) مديرة من روضات مدينة الخبر بالمملكة، وتوصلت الباحثة الى بعض المحاور

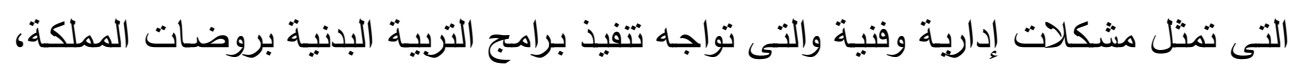


وتضمنت المحاور مشكلات خاصة بى (الطفل - المعلمة - الإثراف الفنى - أولياء الأمور

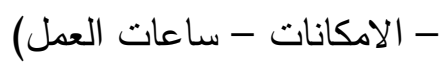

\section{التعليق على الاراسات السابقة:}

يلاحظ من عرض الدراسات السابقة أن جميع الدراسات أكدت على وجود معوقات

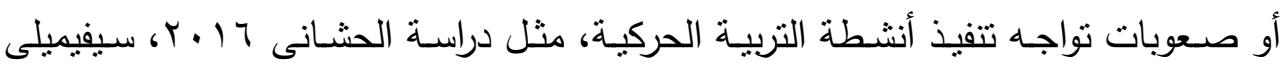

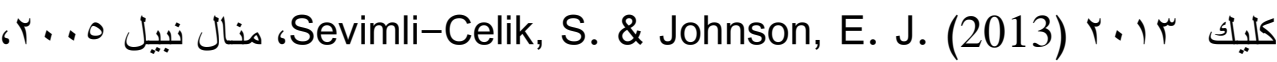

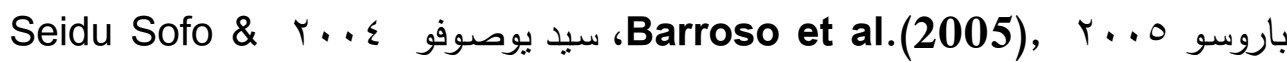
r. . Sola 2004

كمـا أوضـحت بعض نتائج الدراسـات عدم وجود متخصص فـى التربيـة البدنيـة

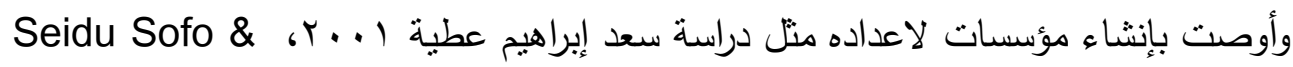
Sola 2004

كما توصلت دراسة أحمد عبد العظيم 999 1، سعد إبراهيم عطية ( +. الى عدم وجود برامج للنشاط الحركى.

أكدت بعض الدراسـات على نقص خبرة وتدريب المعلمـات على أنشطة التربيـة

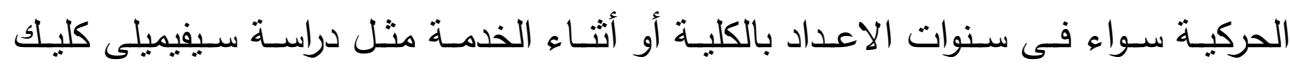
Stdrk, \& ، Sevimli-Celik, S. \& Johnson, E. J. وجنسون rا • r(2013) Sanders 2008 كما أوضحت بعض الدراسات أن أهم المعوقات هو عدم توفر الامكانات والأدوات

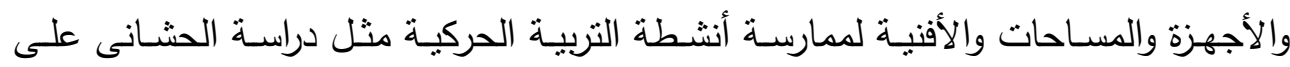

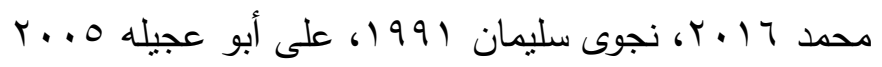
كما ركزت دراسة كلا من Seidu Sofo \& Sola 2004 وسعد إبراهيم عطية

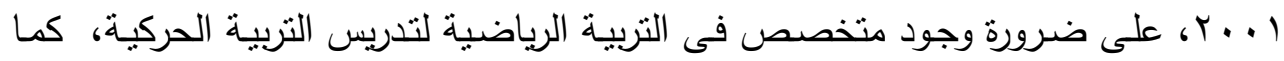

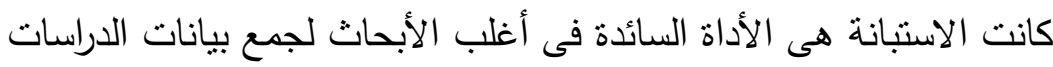


وقد نوصلت جميع الأبحاث الى ضـرورة وضوح أهداف برنـامج التربيـة الحركيـة

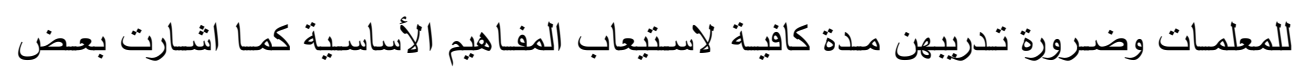
الأبحاث الى ضرورة تقديم تطبيقات عملية حتى تتم الاستفادة.

وفى ظل المنهج الجديد (2,0) الذى أدخلته الوزارة على مؤسسات رياض الأطفال

فى مصر أصبح العبء أكبر على المعلمات وكذا الموجهات وخاصـة أن المعلمات لم ينت تدريبهن على الهنهج الجديد سوى ثلاثة أيسام وهى غير كافيـة لاستبعاب المنهج الجديد وتطبيق أنشطته وقد حفز هذا الباحث على محاولة الكثف عن معوقات تتفيذ أنشطة التربية

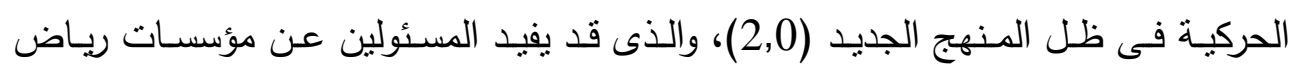

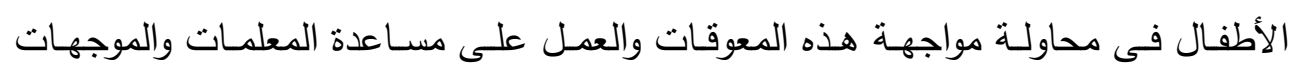

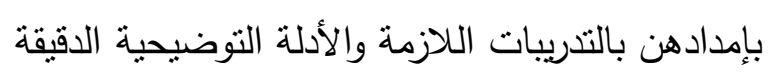

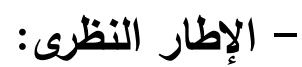

يتتاول الإطار النظرى جزئين الأول عن ما هى التربية الحركية فلسفتها وأهدافها وأسباب تغيير مسمى التربية الرياضية الى التربية الرياضية الصحية، الجزء الثانى يتتاول

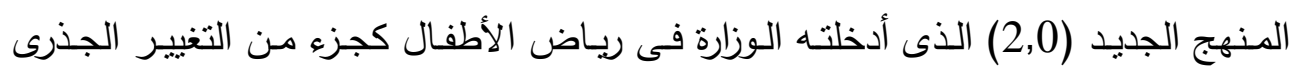

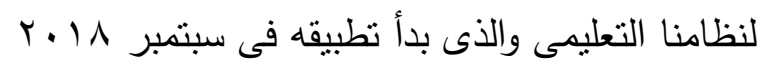

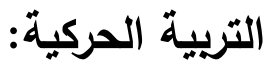

هى ذلك الجزء من التربية الذى ينم عن طريق النشاط البدنى الذى يستخدم الجهاز الحركى

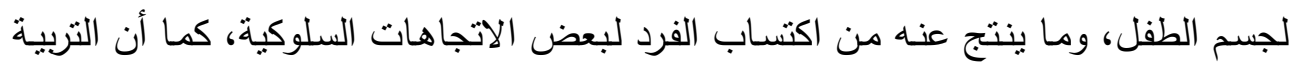

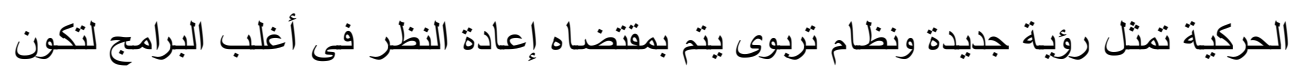

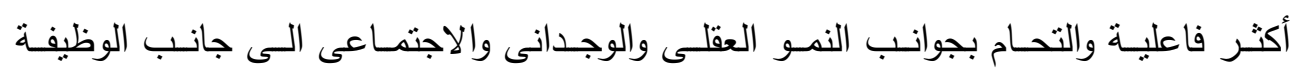
الأساسية فى التتمية البدنية الحالية للطفل والتى تؤهله للمهارات الرياضية مستقبلاً. كما أن التربيـة الحركيـة هـى طريقـة تهدف الى تعليم الطفل المفـاهيم عن طريق

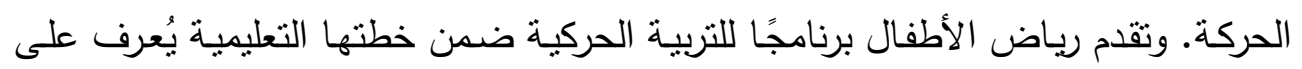


أنه المساحة من منهاج رياض الأطفال التى تقابل احتباجات هذه المرحلة العمرية (ع-7)

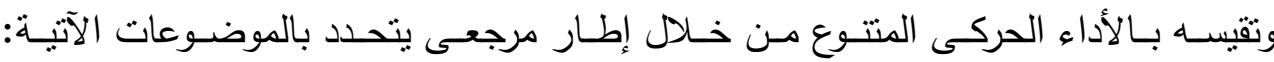

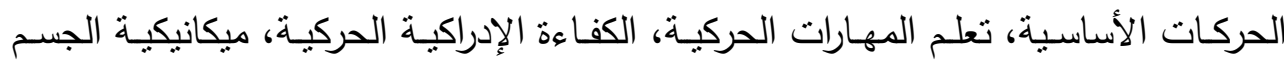

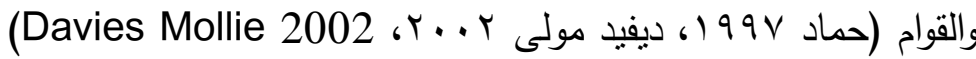
والتربية الحركية هى ذلك النظام التربوى الذى يعتمد بشكل أساسى على الامكانات

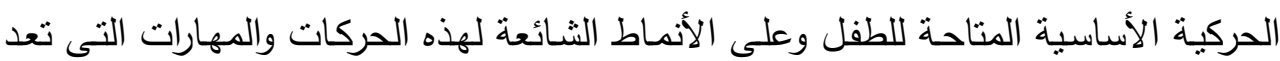

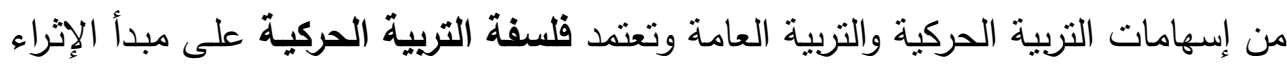

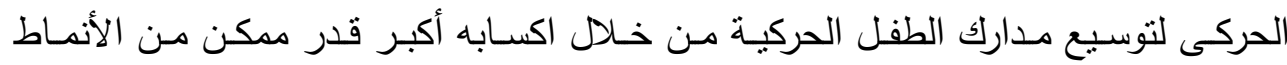
الحركية الثائعة والمهارات الحركية المتتوعة.

\section{- أهمية التربية الحركية:} تظهر أهمية التربية الحركية فى الآتى:

كلما زادت خبرة الطفل الحركية زادت معرفته للبيئة التى حوله ومن خلال التفاعل مع بيئته يكتسب النواحى المعرفية والوجدانية والاجتماعية.

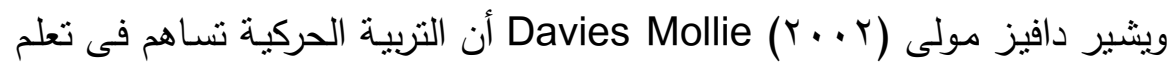
الأطفال من خلال منظور الحركة

والتربيـة الحركيـة تعتبر طريقة بـل أنهـا أصبحت منهج يهدف الـى تعليم الطفل المفاهيم عن طريق الحركة كما أنها تساعد فى دخول الأكسجين الى المـخ مما يزيد من قدرة الطفل على الإدراك الى جانب تتميـة المهارات الأساسية والتى تسـاهم فى التتمية الثـاملة للطفل

تهذف التربية الحركية المقدمة فى رياض الأطفال فى مصر الى: - - - - الوقاية من انحرافات القوام وعلاجها 


\section{مجلة " دراسات في الطفولة والتربية" - جامعة اسيوط}

- - تشيط نمو الحركات الأساسية وأنماطها الثائعة للطفل

-

- - تشتئة الطفل اجتماعيًا على الأنماط النقافية الحركية بمجتمعه

- - الربط بين حركة الطفل وسائر الجوانب السلوكية: المعرفية والوجدانية

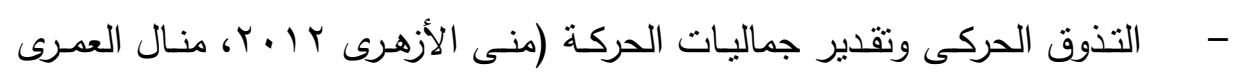

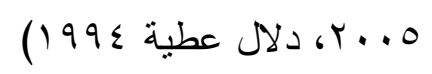

\section{- برنامج التربية الحركية:}

تلكك المساحة من منهاج رياض الأطفال التى يفترض أنها تقابل احتباجات هذه

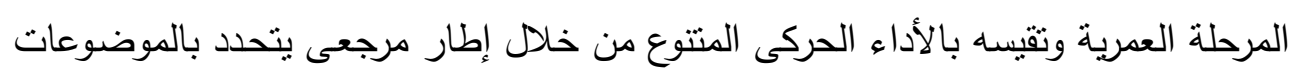

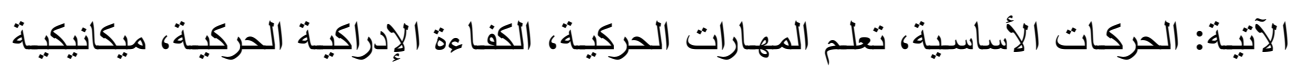

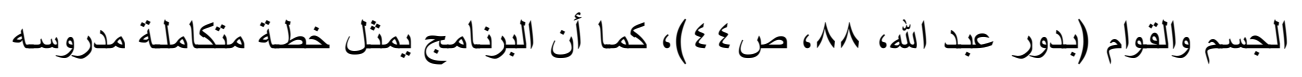

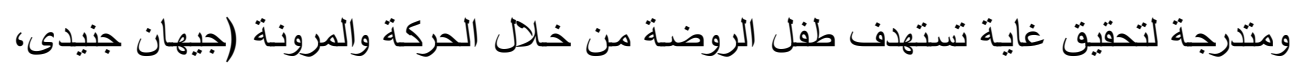

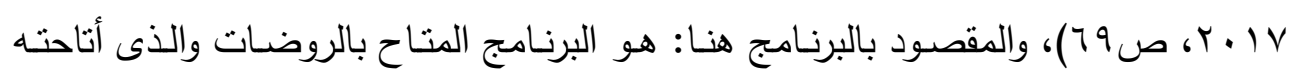

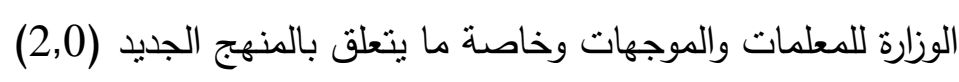
- أسباب تغيير مُسمى التربيـة الرياضية الى التربية الرياضية الصحية بناءً على مـا جاء

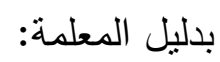

أثنار الدليل الى أن التربية الرياضية حين تسعى الى تحقيق أهدافها التربوية فإنها

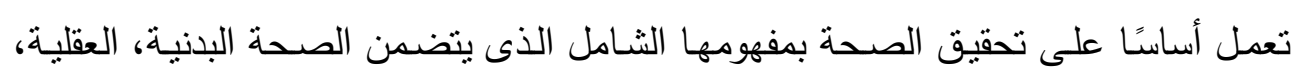
النفسية، الاجتماعية، فالصحة هى ذلك البناء السليم المتكامل للفرد بدنيًا، وعقليًا، ونفسيًا، واجتماعيًا، وليس فقط خلو الجسم من الأمراض والتشوهات.

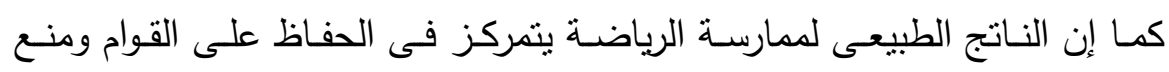

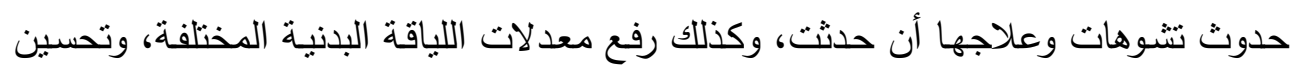

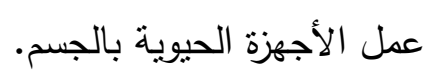


كما أنتـار الدليل أنهه نظرًا لتكامل أهداف التربية الرياضية والتربية الصحية فمن

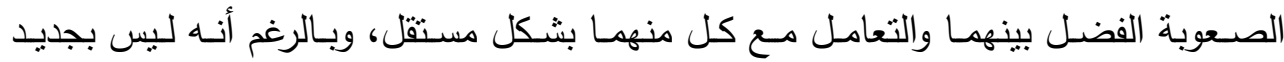

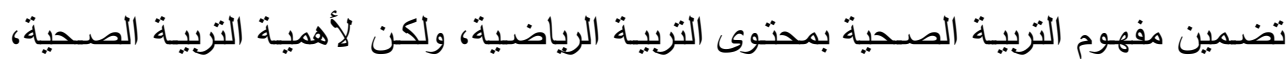

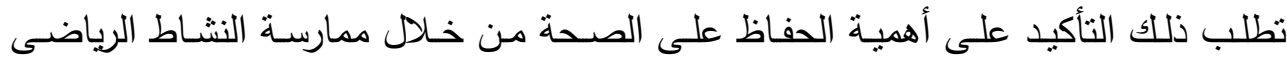

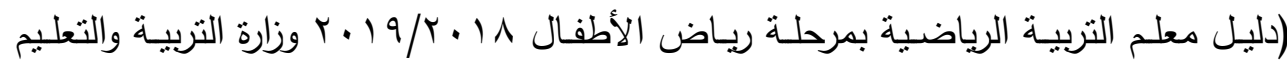

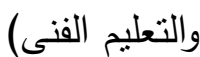
- الجزء الثانى من الإطار النظرى: - - النظ المنهج الجديد (2,0) الذى تم تطبيقه سبتمبر 1 1 ـ ب فى رياض الأطفال بجميع روضات جمهورية مصر العربية.

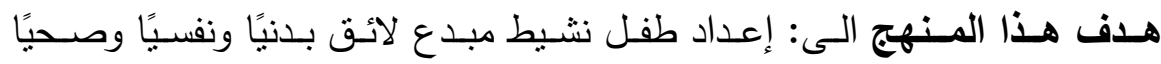
واجتماعيًا

شهدت وزارة التربية والتعليم والتعليم الفنى مرحلة فارقة من تاريخ التعليم فى مصر

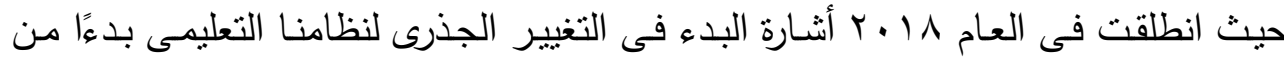

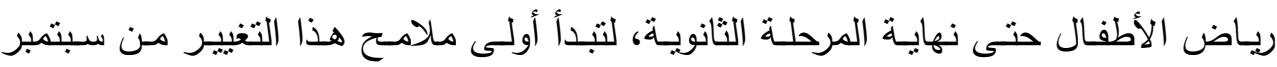

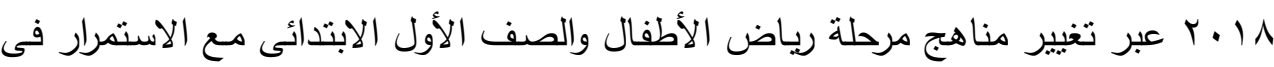

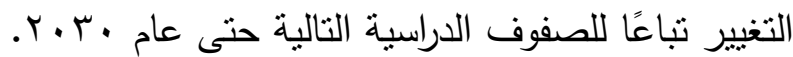

ونظام التعليم والتعلم المصرى الجديد، تم تصحيحه لبناء إنسان مصرى منتم لواطنه ولامته العربية وقارته الأفريقية، مبتكر ، مُبدع يفهم الأختلاف، متمكن من المعرفة والمهارات الحياتية، قادر على التعلم مدى الحياة وقادر على المنافسة العالمية.

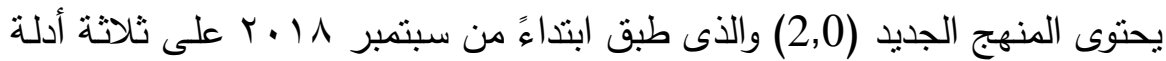
تمثنل محتوى المواد المقررة وهى: دليل المعلم لمهارات التدريس الصـفى للمستوى الأول

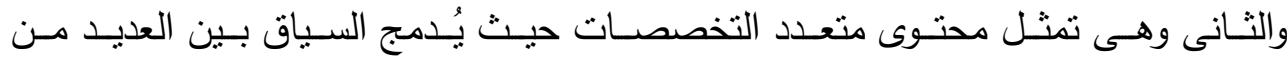
التخصصات فى الدرس، حيث يتدرب التلاميذ ويطبقون مهارات فى الرياضيات والدراسات

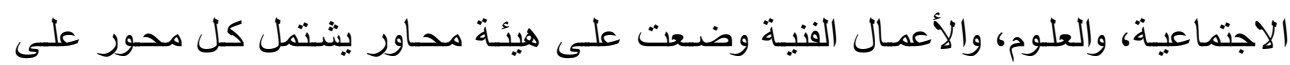


فصـول تتوافق مـع عنـاوين المشـروعات ومواضيعها، تسـخدم المشـروعات كوسيلة للتقيهم

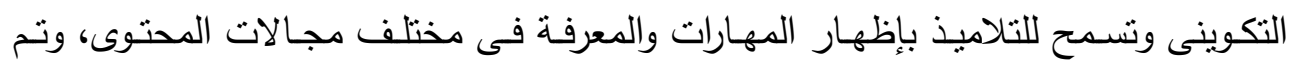
تتظيم الفصول فى ثلاثة مكونات رئيسية هى: إكتثف، تعلم، شارك. وتحتوى البنية الأساسية للمنهج الجديد المحاور الآتية:

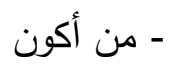

$$
\text { - }
$$

ويشتمل كل محور على تكامل بين المواد، ويتضمن مشاريع كوسيلة للتقبيم البنائى،

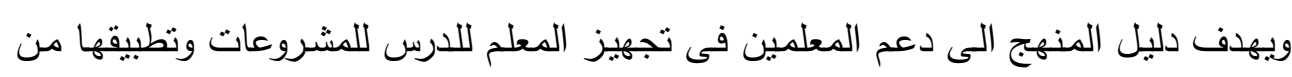

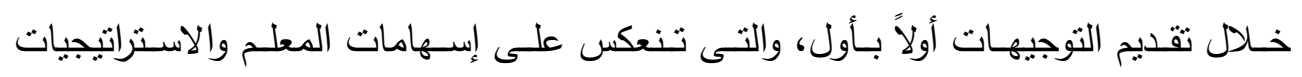
التعليمية وتثنيات إدارة الفصول الدراسية. ولتحقيق منطلبات المنهج الجديد (2,0) بالنسبة لمحتوى متعدد التخصصـات، تم تضمين (ع ا ) مهارة حياتيه يجب تحديدها لكل طفل صُنفت وفق أبعاد التعلم الأربعة:

$$
\begin{aligned}
& \text { - تعلم لتعرف } \\
& \text { - ت تعلم لتعمل - } \\
& \text { - تعلم لتكون } \\
& \text { - تعلم لتعيش مع الآخرين }
\end{aligned}
$$

هذا بالنسبة لدليل متعدد التخصصات وهو الدليل الأول للمسنويين الدليل الثانى هو

دليل اللغة الإنجليزية ويضم الآتى: Scope and Sequence - Introduction 4 Unites: I: Its me 2.My body 3:My

Class 4:My Family 
كذللك يضم Games Bank \& Review ويقع فى سبعون صفحة لكل مستوى والذى يهمنا هنا هو ما يخص التربية الحركية ويتمثل فى هذا الاطار فى دليل معلم التربية

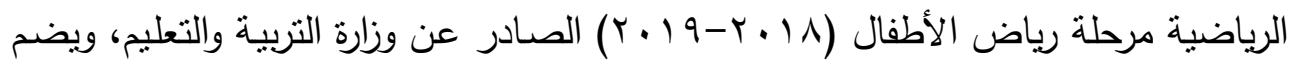

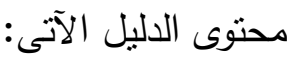

$$
\text { أولا- إطار نظرى: - أن }
$$

إطار تطبيقى للمحاور الأربعة فى ضوء المعايير والمؤشرات

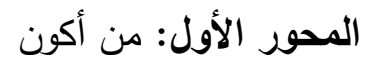

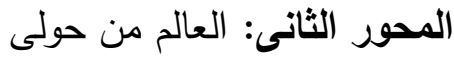

المحور الثالث: كيف يعمل العالم؟

المحور الرابع: النواصل

وتحت كل محور عدد من الدروس ويقع الدليل فى (r I ( ) صفحة واحتوى الإطار

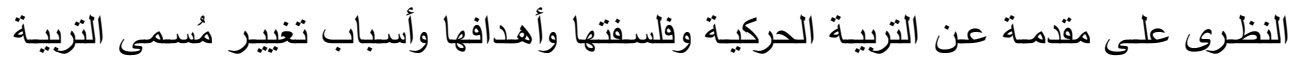
الرياضية الى التربية الرياضية والصحية، وأنشار الدليل بعد ذللك الى إجراءات إعداد منهج رياض الأطفال (المستويين: الأول والثانى): والذى مر بعده خطوات هیى:

1- دراســة خصـائص مرحلـة ريـاض الأطفـال للتعـرف على طبيعـة واحتباجـات تكلـل

المرحلة والتطبيقات التربوية اللازمة لهذه الخصائص وضعت الخصائص ويقابلها

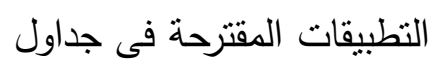

r ب بناء المنهج فى ضوء المحاور الأربعة سابقة الذكر

r- التقييم وهو النقييم المبنى على الأداء للتأكد من مدى تحقيق أهداف منهج التربية الرياضية والصحية واكتشاف المعوقات التى نواجه التتفيذ 


\section{مجلة " دراسات في الطفولة والتربية" - جامعة اسيوط}

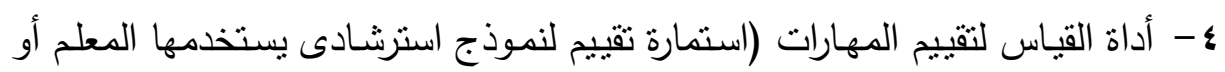
يينى أدوات أخرى يمكن استخدامها للتقبيم التكوينى للتأكد من اكتساب التناميذ المهارات التى يتضمنها الدرس بشكل مرحلى لدئ

\section{ثانيا- الإطار التطبيقى:}

للمحاور الأربعـة فى ضـوء المعايير والمؤشرات والتى تمثنل بنيهـ كل محور من المحاور الأربعة والتى تمثل الأهداف التى يستهدف المنهج تحقيقها (وتغطى المستوى الأول والثانى). بعد ذلك تتاول الدليل المحور وما يحتويه من دروس حيث عرض الآتى: - مهارات أساسية حركية مرتبطة بالمحور - - - مهارات حياتيه خاصة بالمحور - - مفاهيم أساسية مرتبطة بالمحور - مث ن - ماتج التعلم الخاصة بالمحور تم تتاول كل درس على حده من حيث: وصف الدرس - أدواته - أنشطة الدرس وأهداف النشاط وعرض كل نشاط وأهدافه وهكذا حتى ينتهى جميع الدروس فى كل محور ، وفى ني

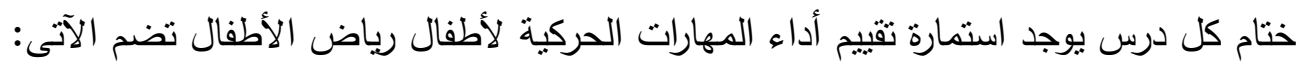
استمارة تقييم أداء المهارات الحركية للطقل

\begin{tabular}{|c|c|c|}
\hline 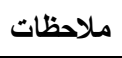 & مستويات الآداء & المهارة المراد قياسها \\
\hline & أقل التوقعات - يلبى التوقعات - يفوق التوقعات & 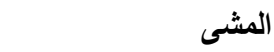 \\
\hline & & 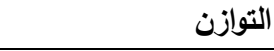 \\
\hline & & 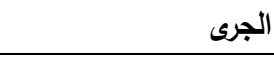 \\
\hline & & 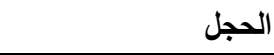 \\
\hline
\end{tabular}


المنهج الجديد (2,0) بمحافظة المنيا (مدينة المنيا)

\begin{tabular}{|c|c|c|}
\hline ملاحظات & مستويات الآداء & المهارة المراد قياسها \\
\hline & & الوثب \\
\hline & & القفز \\
\hline & & التعاون والمشاركة \\
\hline & & النظافة الشخصية \\
\hline & & مهارات أخرى تريد إضافتها \\
\hline
\end{tabular}

ويضم الدليل (•ع () صفحة بالغلاف

ما تم عرضه هو منهج التربية الرياضية والتربية الصحية من خلال الدليل الرسمى

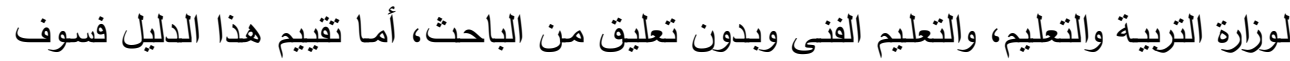

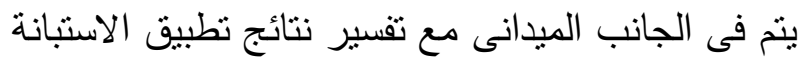
الدراسة الميدانية وإجراعاتها: هدف الاراسة الميدانية:

هدفت هذه الدراسة الى الكثف عن بعض المعوقات التى تواجه المعلمات فى تتفيذ

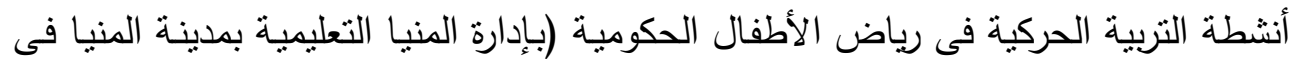
ظل نطبيق المنهج الجديد (2,0)

\section{منهج الاراسة:}

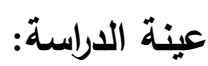

تكونت عينة الدراسة من (Tr) معلمة من معلمات رياض الأطفال الحكومية بمدينة

المنيا، و (1 (1) موجهه وهو العدد الكلى للموجهات بإدارة المنيا التعليمية، تم اختيارها عشوائًاً

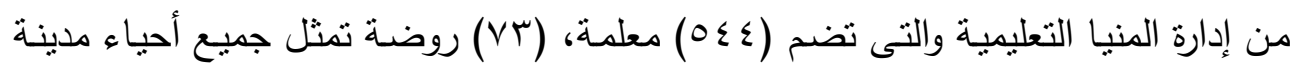
المنيا. وفيما يلى جدول رقم ( ) يوضح توزيع العينة 
مجلة " دراسات في الطفولة والتربية" - جامعة اسيوط

جدول رقم (1): - (1) - توزيع العينة

\begin{tabular}{|c|c|c|c|c|c|c|}
\hline النسبة\%\% & عينة المعلمات & النسبة\% & الموجهات & الموجهات & عدد الروضات فى & المعلمات \\
\hline$\% 4.7$ & r & $\% 1 \ldots$ & 11 & 11 موجهة & 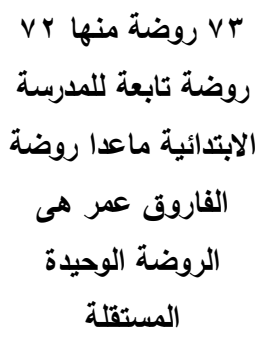 & مع ك 0 \\
\hline
\end{tabular}

جدول رقم (Y): يوضح توزيع عينة المعلمات على الروضات

\begin{tabular}{|c|c|}
\hline عدد المعلمات & اسم الروضة \\
\hline 9 & روضة الفاروق عمر \\
\hline 0 & الحديثة بنات \\
\hline 0 & التجريبية r \\
\hline$r$ & التجريبية 1 \\
\hline$\varepsilon$ & الاخصاص \\
\hline$\varepsilon$ & طه حسين \\
\hline$\varepsilon$ & أبناء الثثرة \\
\hline$r$ & اللمطى \\
\hline 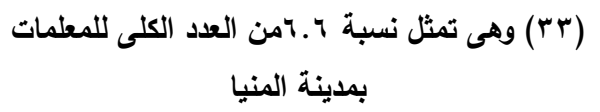 & المجموع \\
\hline
\end{tabular}

وهكذا يوضـح جـدولى )، r أن عينـة المعلمـات بلغـت (Tr) معلمـة أى بنسـبة (7.7\%) من العدد الكلى للمعلمات بمدينة المنيا.

وأن عينة الموجهات بلغت (1') موجهة وهو العدد الكلى للموجهات، كمات أنه

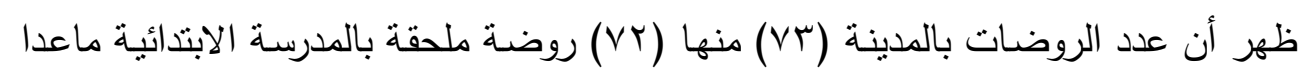
روضة الفاروق عمر هى الروضة الوحيدة المستقلة فى مدينة المنيا. 
اعتمد الباحث فى تجميع بيانات هذه الدراسة على الاستبانة والتى صممت لهذا الغرض حيث اثتملت على خمسة محاور رئيسية، يندرج تحت كل محور منها عدد من

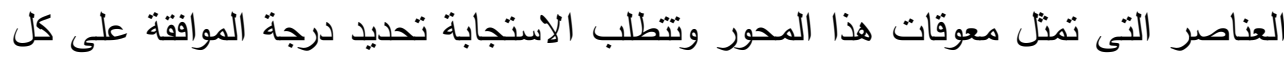

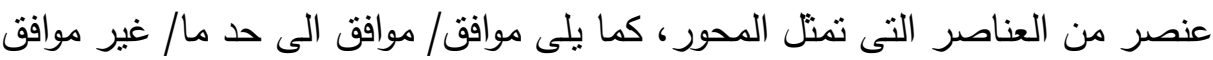

وقد اتبع الباحث فى إعداد الاستبانة الخطوات التالية:

1 - استطلاع رأى عينة من معلمات رياض الأطفال بمدينة المنيا (·r عشرون معلمة)

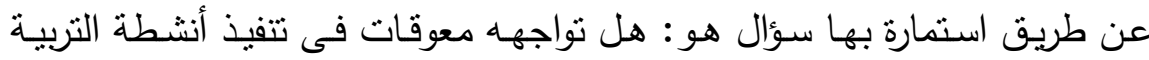
الحركية فى ظل المنهج الجديد وما هى هذه المعوقات وقد ساعدت اجابتهن فى في تحديد بعض العقبات الفعلية التى نواجههن فى هذا المجال.

r - الاطـلاع على بعض الدراسـات السـابقة والكتب والمراجـع ذات العلاقـة بموضـوع الدراسـة ومحاولة الاستفادة من الصياغات العديدة للاستبانات التى تتضمن العديد من المعوقات لتى تواجهه المعلمات فى تتفيذ أنشطة التربية الحركية

r- ولتحديد صدق الاستبانة تم الاعتماد على صدق المحتوى حيث تم عرضها على عدد من المحكمين فى مجال تربية الطفل والتربية الرياضية وبعض أساتذة المناهج

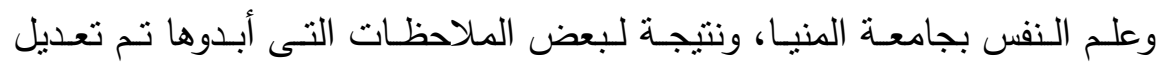
صياغة بعض العناصر تحت كل محور وتم حذف بعض العناصر كذلك.

\section{معوقات خاصة بالتوجيه القنى:}

تم استخدام معامل الثبات بطريقة ألفاكرونباخ لايجاد الثبات الداخلى لكل محور من

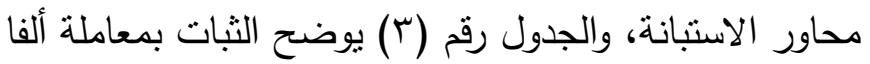


مجلة " دراسات في الطفولة والتربية" - جامعة اسيوط

جدول رقم (ץ): يوضح الثبات بمعامل ألفا

\begin{tabular}{|c|c|c|}
\hline ثبات ألفاكرونباخ & عدد المفردات & 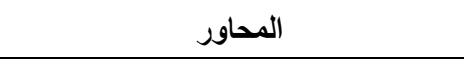 \\
\hline .94 & 1. & معوقات مرتبطة ببرنامج التربية الرياضية \\
\hline.$v V$ & 1. & معوقات مرتبطة بمعلمات رياض الأطفال \\
\hline.$\wedge \wedge$ & 1. & معوقات خاصة بطفل الروضة \\
\hline$\cdot . \vee q$ & 1. & معوقات خاصة بنقص الامكانات \\
\hline.$\wedge \wedge$ & 1. & معوقات خاصة بإدارة الروضة \\
\hline .99 & 1. & معوقات خاصة بالتوجيه الفنى \\
\hline
\end{tabular}

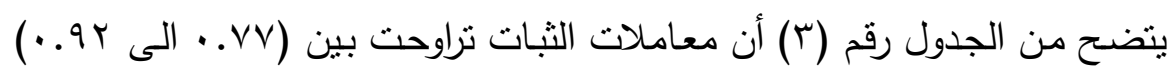

مما يؤكد تحقق الثبات فى نتائج الاستابنة.

صدق الاتساق الاخلى:

للتحقق من الصدق تم استخدام صدق الاتساق الداخلى من خلال ايجاد العلاقة بين

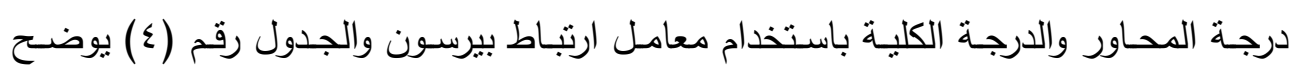

معاملات الارتباط بين درجة كل محور والدرجة الكلية

جدول رقم (؛) : يوضح صدق الاتساق الداخلى

\begin{tabular}{|c|c|c|}
\hline الارجة الكلية & & المحور \\
\hline..$A r$ & معامل الارتباط & \multirow{2}{*}{ معوقات مرتبطة بيرامج التربية } \\
\hline$\ldots 1$ & مستوى الدلالة & \\
\hline. .00 & معامل الارتباط & \multirow{2}{*}{ معوقات مرتبطة بمعلمات رياض الأطفال } \\
\hline$\ldots 1$ & مستوى الدلالة & \\
\hline. $.4 \Lambda$ & معامل الارتباط & \multirow{2}{*}{ معوقات مرتبطة بطفل الروضة } \\
\hline$\cdots 1$ & مستوى الدلالة & \\
\hline. $.0 Y$ & معامل الارتباط & \multirow{2}{*}{ معوقات مرتبطة بنقص الامكانات } \\
\hline$\cdots 1$ & مستوى الدلالة & \\
\hline.$\wedge 0$ & معامل الارتباط & \multirow{2}{*}{ معوقات مرتبطة بالادارة للروضة } \\
\hline$\ldots 1$ & مستوى الدلالة & \\
\hline. $.7 r$ & معامل الارتباط & \multirow{2}{*}{ معوقات مرتبطة بالتوجيه الفنى } \\
\hline$\cdots 1$ & مستوى الدلالة & \\
\hline
\end{tabular}


يتضح من الجدول أن معاملات الارتباط تراوحت بين (ro. • الى r . . ) وجميعها

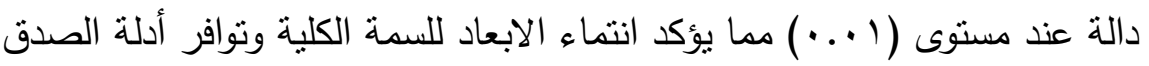

\section{تطبيق أداة الدراسة:}

تم توزيع الاستبانة على عدد ( •0) من معلمات رياض الأطفال بمدينة المنيا وقد

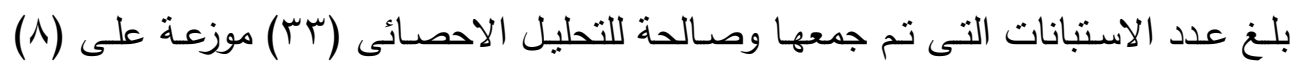
ثمانى روضات كما هو موضح بالعينة

\section{المعالجة الاحصائية:}

للاجابة عن أسئلة الدراسة ثم تحويل استجابات عينة الدراسة على كل عنصر (أو

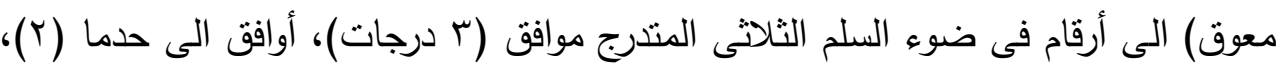
غير موافق (درجة واحدة () وتم الاعتماد على الأساليب الاحصائية التالية: - - المتوسط المرجح والانحراف المعيارى كأساس للمفاضلة فى درجة الموافقة على وجود المعوقات

\section{نتائج الارراسة:}

أولاًَ- إجابـة السـوأل الأول: مـا هـى المعوقات المرتبطـة بيرنـامج التربيـة الحركيـة فى ظل المنهج الجديد (2,0)

جدول رقم (•):المعوقات المرتبطة بالبرنامج

\begin{tabular}{|c|c|c|c|}
\hline البديل السائد البد & 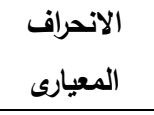 & الحستوسطى & 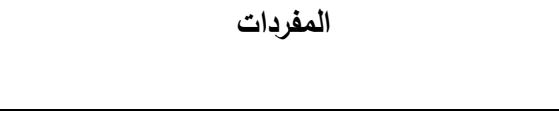 \\
\hline موافق حـ ما & .9 rVYA & r.rIr| & لاتساهم البرامج الحالية فى تنمية ميول الاطفال أو \\
\hline موافق حد ما & $\cdot .911 \cdot \varepsilon$ & r.r.r. & الساعات المخصصة غير كافية \\
\hline موافق حد ما &. .97 .49 & $1 . \wedge \vee \wedge \wedge$ & لاتثجع البرامج على ممارسة النشاط الجماعى \\
\hline موافق حـ ما &. .9 .001 & r.1010 & لاتراعى البرامج الفروق الفردية بين الأطفال \\
\hline 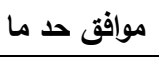 & $. .91+91$ & $r .9 .9$ & لا تساعد البرامج على تنمية حب الاستطلاع \\
\hline
\end{tabular}




$$
\text { مجلة " دراسات في الطقولة والتربية" - جامعة اسيوط }
$$

\begin{tabular}{|c|c|c|c|}
\hline البديل السائد & الانحراف المعيارى & الحسابى المتوسط & 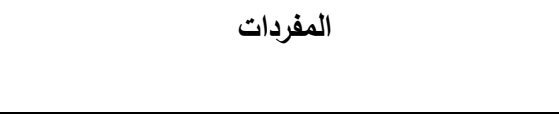 \\
\hline موافق حد ما &.$v \wedge \cdot q r$ & $1 . \vee \wedge \vee q$ & لاتتوافر فى البرامج عوامل الأمن والسلامة \\
\hline موافق حد ما & $\cdot . \vee \wedge . q r$ & $1 . \wedge \vee \wedge \wedge$ & تفتقر الى التنوع فى النشاط \\
\hline 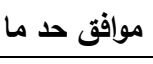 & $. \wedge \leq V Y r$ & $1.979 \mathrm{~V}$ & لاتتيح للأطفال فرصة التنامى \\
\hline موافق حد ما &. . A०Vrr & $1 . \wedge \vee \wedge \wedge$ & لا تساعد فى حل مشكلات الطفل \\
\hline موافق حد ما & $.911 \cdot \varepsilon$ & $1.999 \mathrm{~V}$ & لا تتيح الفرصة لتتمية الابتكار الحركى لدى الطفل \\
\hline موافق حـ ما &. $.74 \wedge \mathrm{rV}$ & r...|r| & مجموع المحور \\
\hline
\end{tabular}

يتضح من الجدول رقم (0) أن المتوسط الحسابى لمجموع المحور هو (1Y (Y)

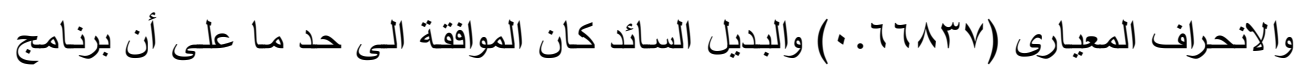

التزبية الحركية لا يساهم فى تتميـة ميول الأطفال ولايشجع على ممارسـة النشـاط الجماعى

ولايراعى الفروق الفرديـة ولا ينمى حب الاستطلاع ولا يساعد فى حل مشكلات الطفل ولا

يتيح الفرصة لتتمية الابتكار الحركى كما أن الساعات المخصصة لهذا النشاط الحركى غير

ثانيا- اجابة السؤال الثانى: ما المعوقات المرتبطة بمعمات رياض الأطفال فى ظل المنهج

$$
\text { الجديد (2,0) }
$$

\begin{tabular}{|c|c|c|c|}
\hline 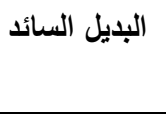 & المعيارى المراف & المسابى المتط & 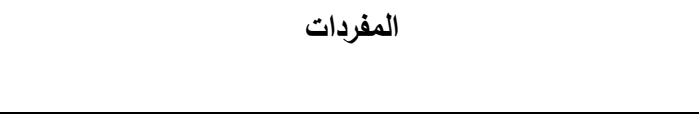 \\
\hline 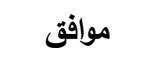 & $\cdot v \cdot \wedge \leq \varepsilon$ & $r . \leqslant r \leqslant r$ & الاعداد المهنى للمعلمات بالكلية لا يتتاسب مع متطلبات العمل \\
\hline 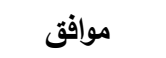 & -. 57479 & r.१९V. & عدد المعلمات لا يتناسب مع عدد الأطفال \\
\hline موافق حد ما & $. V I r \leq \leq$ & $r . \leqslant \wedge \leqslant \Lambda$ & نقص الدورات التدريبية أثناء الخدمة خاصة مع الموجهات \\
\hline 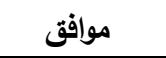 & $\cdot . r \cdot r \cdot r$ & ห.ศTฯ & عدم تناسب العائد المادى مع عبء العمل \\
\hline 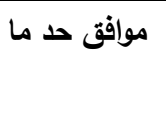 & $\cdot v \cdot \wedge \leq \leq$ & $r . \leqslant r \leqslant r$ & قلة خبرة بعض المعلمات مما يؤثر على قدرتها على تحقيق الهداف التربية البدنية \\
\hline 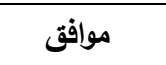 &.$r \cdot r \cdot r$ & r.7ry & عدم تناست العائد المادى مع عبء العمل \\
\hline
\end{tabular}

جدول رقم (؟): المعوقات المرتبطة بالمعلمات 
د/ طارق سلام سيد أحمد سلام

بعض المعوقات التى تواجة تنفيذ أنثطة

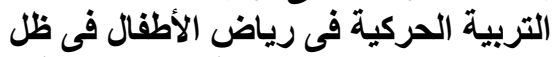
المنهج الجديد (2,0) بمحافظة المنيا (مدينة المنيا)

\begin{tabular}{|c|c|c|c|}
\hline البديل السائد & الانحراف & الحسابى المتوسط & المفردات \\
\hline 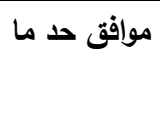 & $\cdot V \cdot \wedge \leq \varepsilon$ & $r . \leqslant Y \leqslant r$ & قلة خبرة بعض المعلمات مما يؤثر على قدرتها على تحقيق أهداف التربية البدنية \\
\hline موافق حـ ما & .00 .090 & $r . \leq 0 \leq 0$ & عدم وجود مساحة كافة لكى لدرس التربية البذنية \\
\hline موافق حـ ما &.$\vee \vee 70 \ldots$ & Y..9.9 & كثرة شكاوى الامهات \\
\hline موافق حد ما & $\cdot .2111$ & $r . \leqslant 0 \leqslant 0$ & كثرة المسئوليات والواجبات الاضافية على المعلمات \\
\hline
\end{tabular}

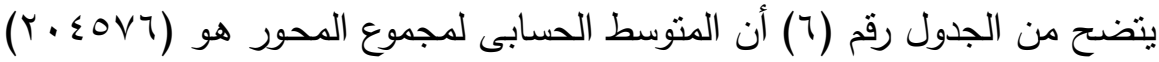

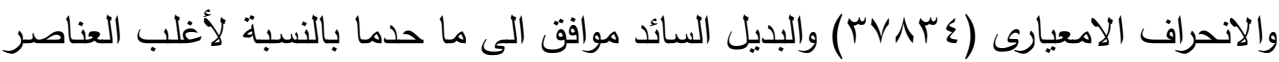
ماعدا ثلاثة عناصر حيث جاء البديل موافق الى حد ما بالنسبة لأغلب العناصر ماعدا

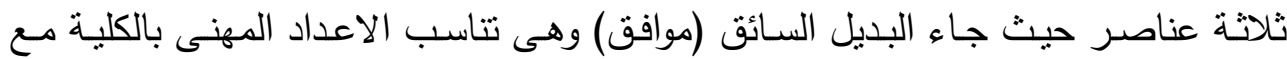
متطلبات العمل عدد المعلمات عدد المعلمات لاتتاسب مع عدد الأطفال وعدم تتاسب العائد

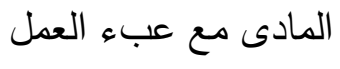

ثالثا- اجابة السؤال الثالث: ما المعوقات المرتبطة بطفل الروضة فى ظل المنهج الجديد $(2,0)$

جدول رقم (V):المعوقات المرتبطة بطقل الروضة

\begin{tabular}{|c|c|c|c|}
\hline البديل السائد البد & الانحراف & المستوسط المسط & المفردات \\
\hline موافق حـ ما &. .74 . & $r . r \leq Y \leq$ & ضعف الناحية الصحية لدى بعض الأطفال \\
\hline 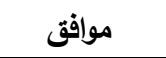 & $.0 Y 9 \leq \leqslant$ & r. . १V. & زيادة عدد الأطفال فى الصفل \\
\hline موافق حد ما & $\because \vee \vee \vee Y \wedge$ & r.rrT & عزوف بعض الأطفال عن ممارسة الأنثطة البذنية \\
\hline موافق حـ ما &.$\vee V T 1 Y \wedge$ & r.YVYV & عدم وعى بعض أولياء الأمور بأهمية ممارسة \\
\hline موافق حـ ما & $.918 \cdot 1$ & r.1A11 & لا تشبع الأنشطة الحركية احتياجات وميول الأطفال \\
\hline 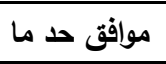 & $.940 \leq 1$ & r..... & لا تراعى المعلمة الفروق الفردية بين الأطفال \\
\hline موافق حد ما & $. . \wedge \leqslant V Y r$ & $1.979 \mathrm{~V}$ & تحيز بعض المعلمات لأطفال بعينهم من حيث \\
\hline موافق حد ما & . vrra & Y.. q. q & عدم قرة بع الآباء على شراء ملابس رياضية مما \\
\hline
\end{tabular}


مجلة " دراسات في الطقولة والتربية" - جامعة اسيوط

\begin{tabular}{|c|c|c|c|}
\hline البديل السائد & الانحراف المعيارى & المستوسط المسط & المفردات \\
\hline موافق & 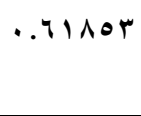 & r.010r & حب الأطفال للحرية فى أداء النشاط الحركى \\
\hline موافق حد ما &.$v r 4 q r$ & r.111 & 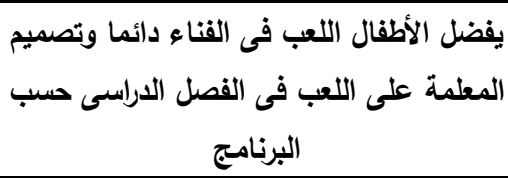 \\
\hline موافق حد ما & .04 .99 & $r . r \leq \wedge 0$ & محور المحور \\
\hline
\end{tabular}

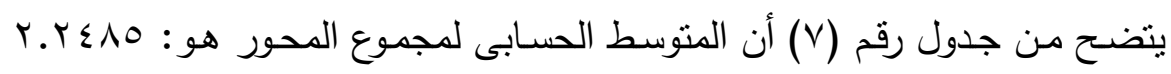
والانحراف المعيارى 99 • سه. · والبديل السائد موافق الى حد ما بالنسبة لأغلب العناصر،

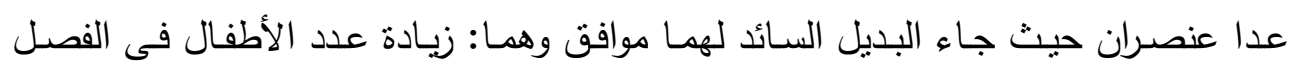
وحب الاطفال للحرية فى أداء النشاط الحركى بدون جديه من المعلمة

رابعا- اجابـة السوأل الرابـع: مـا المعوقات المرتبطة بالامكانات المتاحة بالروضـة فى ظل

$$
\text { المنهج الجديد (2,0) }
$$

جدول رقم (^):المعوقات المرتبطة بالامكانات المتاحة بالروضة

\begin{tabular}{|c|c|c|c|}
\hline البديل السائد & الانحراف & الحستوسطى & المفردات \\
\hline 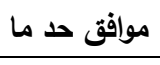 & $\cdots 0.11$ & $r . \leq r \leq r$ & نقص الميزانية المتوفرة للارتقاء برياض الأطفال \\
\hline 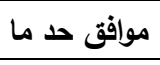 & .0 .119 & $r . \leqslant Y \leqslant r$ & قلة الوسائل التعليمية التى تعين على تنفيذ التربية البذنية \\
\hline موافق & . . $\$ 94 r$. & Y.7.71 & عدم توافز أماكن لتنفيذ النشاط الحركى مثل الحدائق والأفنية \\
\hline موافق حد ما & $\cdot . \vee \wedge \cdot 9 \mu$ & r.YIYI & عدم توافر أجهزة وأدوات للتربية البدنية \\
\hline موافق & .00 .070 & Y.0 000 & افتقار الروضة لحظيرة حيوانات \\
\hline 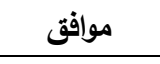 & $\because \leqslant \vee \wedge \vee 1$ & ห.7ร7V & افتقار الروضة للمرافق الصحية المناسبة \\
\hline موافق حـ ما & $. \wedge \leq V Y r$ & $r . \cdot r \cdot r$ & لا توجد وسائل أمن وسلامة بالملاعب \\
\hline موافق حد ما & .vra^r & r.MIYI & عدم توفر قصص حركية بالمكتبة \\
\hline موافق حد ما &. $.790 V \mathrm{r}$ & $Y . \leqslant 0 \leqslant 0$ & عدم وجود قاعات للاحتفالات \\
\hline 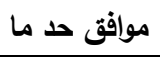 &.$v 1111$ & Y. $\leqslant 0 \leqslant 0$ & عدم وجود قاعات شتوية لممارسة التربية البدنية \\
\hline موافق حد ما & $\cdot r \mu \cdot r \leq$ & r.sı^r & مجموع المحور \\
\hline
\end{tabular}


د/ طارق سلام سيد أحمد سلام

بعض المعوقات التى تواجة تنفيذ أنثطة

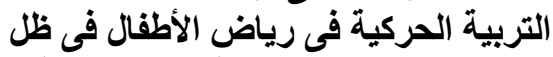
المنهج الجديد (2,0) بمحافظة المنيا (مدينة المنيا)

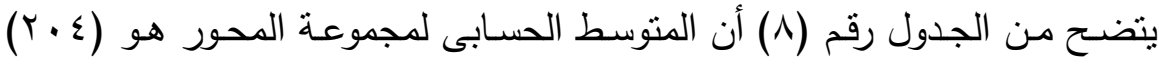

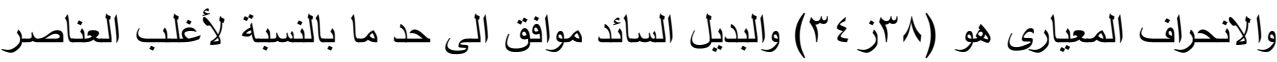

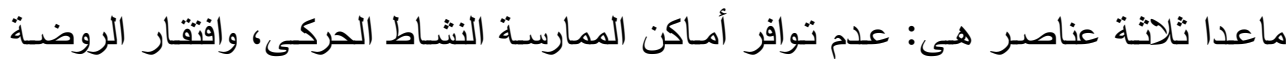
لحظيرة حيوانات وافتقار الروضة للمرافق الصحية المناسبة

خامسـا- السـؤال النـامس: مـا المعوقات المرتبطـة بـالادارة فى الروضـة فى ظل المنهج الجديد (2,0)

جدول رقم (9):المعوقات المرتبطة بإدارة الروضة

\begin{tabular}{|c|c|c|c|}
\hline البديل السائد & 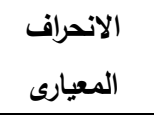 & المستوسط & 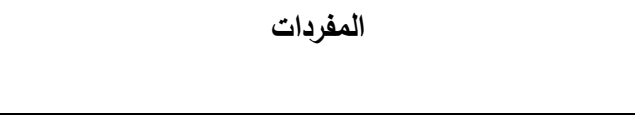 \\
\hline 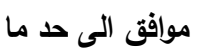 &. $.7 v 1 r v$ & r. $\ \neg \wedge \wedge$ & عدم الاهتمام الادارة بالتربية البدنية والحركية \\
\hline موافق الى حد ما & $. \vee V T I Y \leq$ & 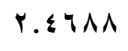 & عدم دعم المعلمات فيما يطلبن \\
\hline 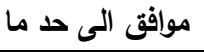 & $\cdot . \wedge \varepsilon \cdots r$ & r.. Tro & تسلط الادارة وعدم مرونتها \\
\hline موافق الى حـ ما & $\cdot . \uparrow \wedge \cdot r \cdot$ & r.IAVO & عدم فهم الادارة المدرسية برامج وتدريس التربية البدنية \\
\hline 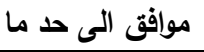 & . V4า & r.107r & عدم اهتمام الادارة بمشكلات الأطفال ولا العمل على حلها \\
\hline موافق الى حد ما & 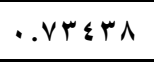 & r...9rर & تدخل بعض المديرين فى عمل المعلمات \\
\hline موافق الى حـ ما &. .779 .1 & r. $\left\{r_{V}\right.$ & عدم توفر الاجهزة والأدوات التى تساعد على أداء التربية \\
\hline موافق الى حد ما & .v०qr० & r. $\left\{r V_{0}\right.$ & تدخل بعض المديرين فى عمل المعلمات \\
\hline 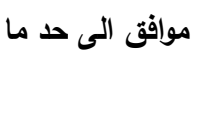 & $\cdot . \vee \bullet 4 . r$ & r.s. Tr & عدم توفر الأجهزة والأدوات التى تساعد على أداء التربية \\
\hline موافق الى حد ما &.$\wedge \ldots \vee 1$ & r.. Tro & تكليف المعلمات بأعمال اضافية وأعمال ادارية \\
\hline موافق الى حد ما & $.0 r \leqslant .9$ & r.rVAI & محور المحور \\
\hline
\end{tabular}

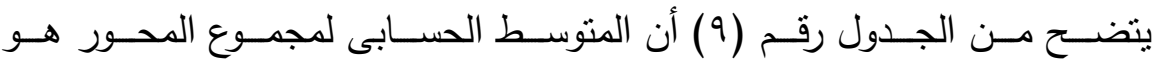

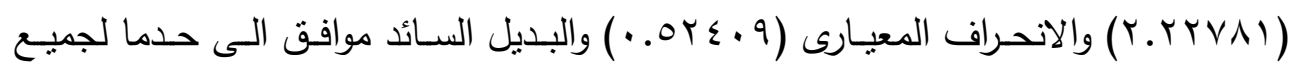
العناصر أى أن المعلمات يوافقن الى حدما على وجود عوائق مرتبطة بإدارة الروضة 


\section{مجلة " دراسات في الطقولة والتربية" - جامعة اسيوط}

سادسا - السؤال السادس: ما المعوقات المرتبطة بالتوجيه الفنى فى ظل المنهج الجديد $(2,0)$ جدول رقم ( • 1):المعوقات المرتبطة بالتوجيه القنى فى ظل المنهج الجديد (2,0)

\begin{tabular}{|c|c|c|c|}
\hline البديل السائد & 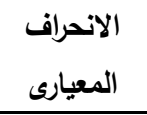 & الحستوسطى & المفردات \\
\hline موافق حـ ما &..$\wedge 99 \curlyvee \wedge$ & Y.. Y. T & قلة وجود موجهات متخصصات فى رياض الأطفال \\
\hline 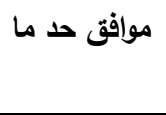 & .ArTAV & Y.. Y. & عدم توفر بطاقة لتقييم اداء المعلمات فى \\
\hline موافق حدما & .AYษAV & $1.949 \leq$ & قلة عدد مرات الزيارات من الموجهة \\
\hline موافق حد ما & $.71 r a r$ & $1.80 \vee 7$ & تحيز بعض الموجهات فى عملية التقويم \\
\hline مواف حدما & $. \wedge 74 . r$ & r..... & الموجه ليس لايه القدره على الابتكار \\
\hline موافق حدما & .vrasr & $1 . \vee \wedge \vee q$ & عدم وجود رؤية واضحة لطبيعة عمل \\
\hline 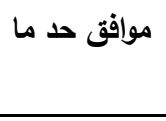 & . VVVYA & $1.774 \mathrm{~V}$ & عدم وجود بطاقة خاصة لتقييم اداء الطقل \\
\hline موافق حـ ما & $\because$ vroqA & $1.747 \mathrm{~V}$ & القيام بالزيارات للمدارس عن طريق أوقات غير مناسبة \\
\hline موافق حد ما & $\because v \leq r r q$ & $1.747 \leq$ & قلة التعاون بين المعلمات والموجهات \\
\hline موافق حـ ما & . VVVYA & $1.747 \mathrm{~V}$ & عدم اعطاء فرصة للمعلمات للمناقشة \\
\hline موافق حد ما & $.0074 \leq$ & $1 . \wedge r \leq r$ & مجموعة البعد \\
\hline موافق حد ما & .roorr & r.r.VA & المجموع الكلى للمحاور \\
\hline
\end{tabular}

يتضــح مـن الجـدول رقـم ( • () أن المتوسـط الحسـابى لمجموعـة المحسور هـو

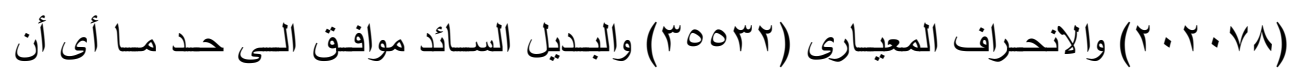
المعلمات موافقات الى حد ما أن هناك معوقات مرتبطة بالتوجيه الفنى 
سابعا- السؤال السابع: هل توجد فروق فى المعوقات ترجع الى عدد سنوات الخبرة؟ جدول رقم (1 1 ) : المعوقات التى ترجع الى سنوات الخبرة

\begin{tabular}{|c|c|c|c|c|}
\hline \multicolumn{5}{|c|}{ الرتب } \\
\hline مجموعة الرتب & متوسط الرتب & العدد & مستويات الخبرة & \\
\hline rrv... & $1 \leq .19$ & 17 & خبرة أقل من V V & \multirow{2}{*}{ معوقات مرتبطة ببرامج } \\
\hline r & 19.70 & iv & خبرة أعلى من 1 | & \\
\hline r^q.०. & $11 . .9$ & 17 & خبرة أقل من V V & \multirow{2}{*}{ معوقات مرتبطة بمعلمات } \\
\hline rvi.0. & $10.9 \mathrm{~V}$ & iv & خبرة أعلى من 1 | & \\
\hline ror.o. & $10.1 \leq$ & 17 & خبرة أقل من V V & \multirow{2}{*}{ معوقات مرتبطة بطفل } \\
\hline r.v.o. & $11 . .9$ & iv & خبرة أعلى من 1 | & \\
\hline מrr... & $1 \leq .07$ & 17 & خبرة أقل من V V & \multirow{2}{*}{ معوقات مرتبطة بنقص الامكانات } \\
\hline rr^... & 19.89 & iv & خبرة أعلى من 1 1 & \\
\hline $19 \ldots$ & 11.11 & 17 & خبرة أقل من V V & \multirow{2}{*}{ معوقات مرتبطة بالادارة } \\
\hline rrı... & r.1. & IV & خبرة أعلى من 1 1 & \\
\hline rro... & $1 \leq . .7$ & 17 & خبرة أقل من V V & \multirow{2}{*}{ معوقات مرتبطة بالتوجيه } \\
\hline rrq... & 19.87 & iv & خبرة أعلى من 11 & \\
\hline rio... & & 17 & خبرة أقل من V V & \multirow[t]{2}{*}{ الدرجة الكلية } \\
\hline rir... & 19.07 & iv & خبرة أعلى من 1 1 & \\
\hline
\end{tabular}

اتضح من اختيار مان وتينى فى جدول رقم (1) (1) عدم وجود فروق ترجع للخبرة

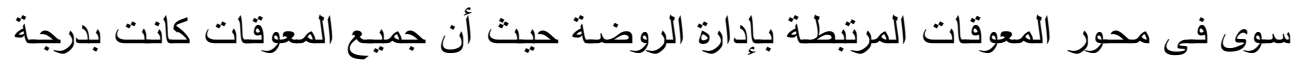
تتراوح من المتوسطة للثديدة إلا أن معوقات الادارة شعر بها الأكثر خبرة 
مجلة " دراسات في الطفولة والتربية" - جامعة اسيوط

جدول رقم (r ( ): يبين نتيجة اختبار مان وتينى والنتيجة الحرجة ومستوى الدلالة

\begin{tabular}{|c|c|c|c|c|c|c|c|}
\hline الارجة & مرتبطة & لل مرتبطة & معرتبطة & مرتبطة بطقل & مربتمة معتبة & معرتبطة & \\
\hline$\vee q . .$. & $\wedge 9 . .$. & $0 \leq \ldots$ & q ..... & $118.0 \ldots$ & $111.0 \ldots$ & $91 . .$. & ميتنى \\
\hline $1 . \wedge \leq \wedge-$ & $1.8 \ldots-$ & Y.V৭V- & $1 . \leqslant 1 Y-$ & $.7 V \cdot-$ & - . . & $1.9 r r-$ & القرجة \\
\hline$\ldots 70$ & $\cdots \wedge 9$ & $\ldots$. &. .101 & $.0 . r$ & .orv & $\cdot .1 \cdot r$ & مستوى الدلالة \\
\hline
\end{tabular}




\section{المراجع}

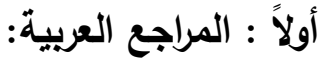

- أحمد عبد العظيم حسن (1997 ()): مشكلات التربية الحركية فى رياض الأطفال بمحافظة

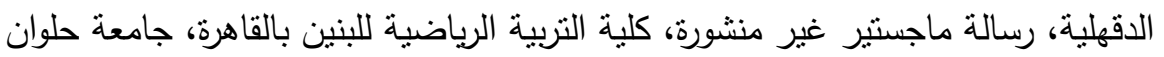
- الحشانى على محمد (7 1 • ץ): معوقات استخدام أنشطة وبرامج التربية الحركية بمؤسسات

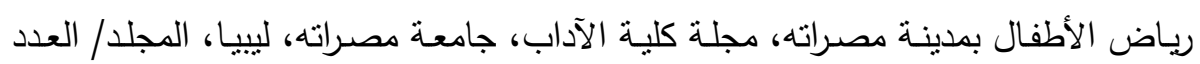

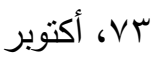

- الحشانى، على محمد (7 ( r): معوقات استخدام أنشطة وبرامج التربية الحركية بمؤسسات

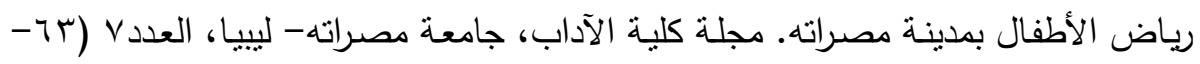

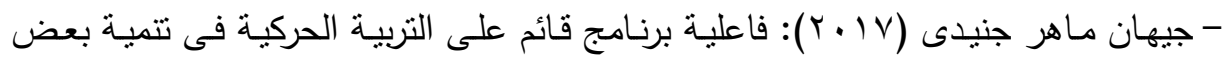

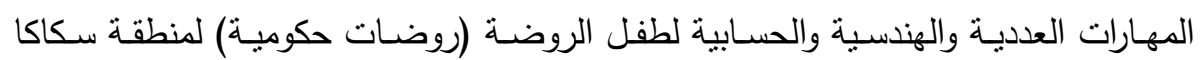

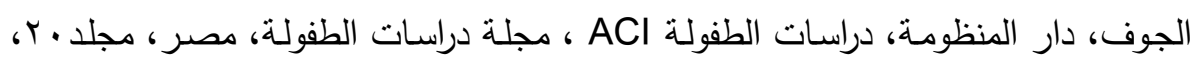

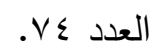

- دلال فتحى عطية (§99 (1)): تقويم واقع التربية الحركية برياض الأطفال، رسالة ماجستير غير منشورة، معهد الدراسات والبحوث التربوية، جامعة القاهرة.

- دلال فتحى يوسف (؟ 99 ()): تقويم واقع التربية الحركية برياض الأطفال، رسالة ماجستنير غير منشورة، معهد الدراسات والبحوث التربوية، جامعة القاهرة

- سعد إبراهيم محجوب عطية ( ( . ب): دراسة تحليلية لبرامج النشاط الحركى لرياض الأطفال

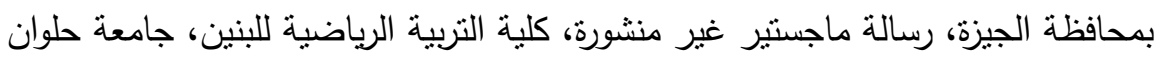

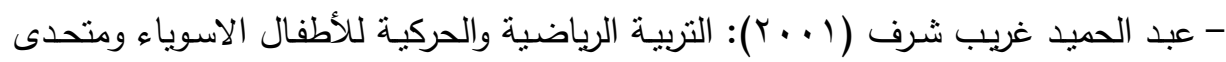
الإعاقة، مركز الكتاب للنشر ، القاهرة 


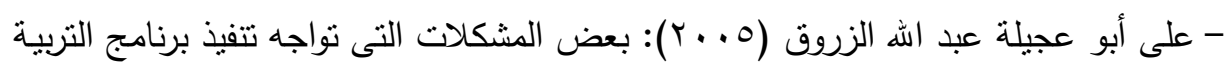
الحركية بمرحلة رياض الأطفال بشعبة طرابلس، رسالة ماجستير غير منشورة، كلية التربية البدنية، جامعة طرابلس

- مفتى إبراهيم حماد (997 ( )): التربية الحركية وتطبيقاتها لرياض الأطفال والمرحلة الابتدائية، مؤسسة المختار ، القاهرة.

- منال نبيل العمرى (0 . ץ): برنامج مقترح للتغلب على معوقات استخدام التربية الحركية فى منهج الأنشطة فى مرحلة رياض الأطفال، رسالة ماجستير، جامعة القاهرة، معهد الدراسات

$$
\text { والبحوث التربوية }
$$

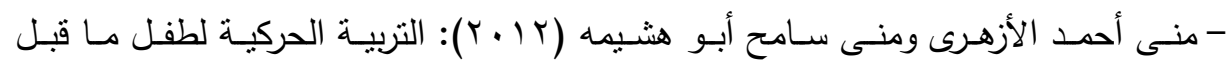
المدرسة، مكتبة الأنجلو المصرية، القاهرة

- نجوى سليمان متولى ( 99 (1) المشكلات الإداريـة والفنيـة والتى تواجـه تتفيذ برامج التربيـة الرياضية برياض الأطفال بالمملكة العربية السعودية، بحث منشور، المجلد السادس، العدد الثانى، مجلة علوم وفنون الرياضية، جامعة حلوان، القاهرة.

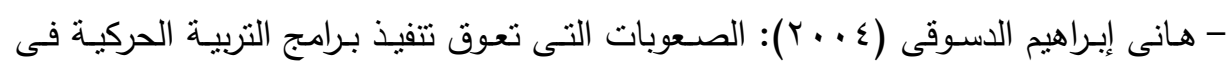

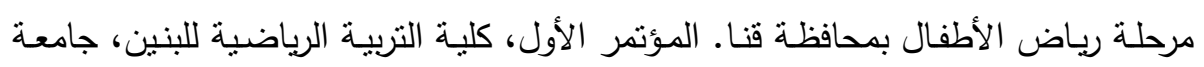

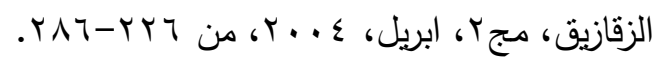

- وزارة التربيـة والتعليم والتعليم الفنى (9 ( • r): دليـل معلم التربيـة الرياضـية مرحلـة ريـاض

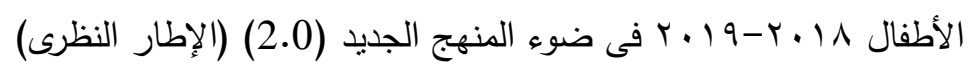

ثانياً : المراجع الأجنبية:

- Barroso et al., (2005): Self_reported Barriers to Quality Physical Education by Physical Specialists in Texas U.S.A. Journal of School Health 57 (8), 313-319

- Basch, C. E. (2010): Healthier Students are Better Learners. Equity Matters, 6 New York.

- Davies Mollie (2002): Helping Children to Learn through Movement Perspective, London, New York

- Galhue, D. (1982) op. et. 
- Galhue, David. (1996): Understanding Motor Development in Childern, John Wickly \& Sons, New York.

- Paley, V. (2004): A Child's Work: The Importance of Fantasy Play. Chicago University Press

- Seidu Sofo \& A Sola (2013): Perceived Barriers to Teaching Movement and Physical Activity to Kindergater in Gihana. Journal of Education and practice. Vol.6, No.36

- Sevimli-Celik, S. \& Johnson, E. J. (2013): I need To move and so do the children, International Education Studies, 6(5), I-10. https://doi.org/10.5539/ies.v6n5p1

- Stork, S. \& Sanders, S. W. (2008): Physical education in Early Education. The Elementary Sch. Journal, 198, 197-206

- Timmons, B. W., Leblane et all. (2012); Systemotic View of Physical Activity and Health in the early years (0-4Years) Applied Physiology. Nutrition and Metabolism. 37, 773-22

- Trudeathe, F. \& Shepard, R. (2008): Physical Education International Journal of Behvioral Nutrition and PE, 5(10) 